\title{
Cultural change and the migration choice
}

\author{
Mauro Lanati ${ }^{1} \cdot$ Alessandra Venturini $^{1}$ (D)
}

Accepted: 15 April 2021 / Published online: 11 June 2021

(C) The Author(s) 2021

\begin{abstract}
Cultural differences play an important role in shaping migration patterns. The conventional proxies for cross country cultural differences, such as common language; ethnicity; genetic traits; or religion, implicitly assume that cultural proximity between two countries is constant over time and symmetric. This is far from realistic. This paper proposes a gravity model for international migration which explicitly allows for the time varying and asymmetric dimensions of cultural proximity. In accordance with Disdier, Tai, Fontagné, Mayer (Rev World Econ, 145(4):575$595,2010)$ we assume that the evolution of bilateral cultural affinity over time is reflected in the intensity of bilateral trade in cultural goods. The empirical framework includes a comprehensive set of high dimensional fixed effects which enable identification of the impact of cultural proximity on migration over and beyond the effect of pre-existing cultural and historical ties. The results are robust across different econometric techniques and suggest that positive changes in cultural relationships over time foster bilateral migration.
\end{abstract}

Keywords Migration · Trade in cultural goods · Gravity model

JEL Classification $\mathrm{F} 16 \cdot \mathrm{F} 22 \cdot \mathrm{Z} 10$

\section{Introduction}

Harris and Todaro (1970) interprets migration flows in terms of the wage differential between sending and destination countries and the associated cost of the journey. This interpretation has been seen as insufficient in explaining migration patterns.

Alessandra Venturini

alessandra.venturini@unito.it

Mauro Lanati

mauro.lanati@eui.eu

1 Migration Policy Centre (EUI), Robert Schuman Centre of Advanced Studies (EUI), Florence, Italy

2 University of Torino, Turin, Italy 
Indeed, the presence of fairly small migration flows-both within and between countries-has shifted the focus of the literature away from economic factors, despite very strong economic drivers such as unemployment and wage differentials (see Barro \& Sala-i-Martin, 1995). More attention is now given to non-pecuniary determinants of migration decisions, such as cultural relationships.

Earlier empirical research has shown that measures of cultural proximity-e.g. bilateral linguistic, religious and genetic distance as well as colonial links-are often more important determinants of migration patterns than traditional economic variables. ${ }^{1}$ The work of Belot and Ederveen (2012), in particular, provides sound empirical evidence on the central role of cultural distance in shaping migration patterns. They analysed the impact of several dimensions of cross-country cultural barriers using a set of indicators describing bilateral religious and linguistic distance. They also included survey-based composite measures of cultural distance, such as the Hofstede or the Inglehart and Baker indexes, with all of them fostering bilateral emigration rates. Similar proxies of cultural proximity have been found by Belot and Hatton (2012) to be more important determinants of educational selectivity in immigration than wage incentives or a selective immigration policy.

All of these measures, however, have been challenged in their capacity to effectively capture some important dimensions of cultural relationships (see Shenkar 2001; Li et al. 2017; Felbermayr \& Toubal 2010; Tung \& Verbeke 2010), which we understand as being particularly relevant for international migration. More specifically, they are unlikely to be able to fully capture a broader notion of cultural proximity which hinges on the acknowledgement that cultural relationships are subject to variation over time. ${ }^{2}$ Measured at a single point in time, existing measures of cultural proximity are considered to be constant. However, this is not realistic as culture measured when the decision to migrate was made may have changed by the time that culture is measured. Recent macro indexes of cultural distance based on Hofstede's cultural dimensions do not account for the time dimension (see Kaasa et al., 2016) and they are mostly confined to European countries that are more culturally alike. ${ }^{3}$ The assumption of stability is particularly unrealistic when we consider the last two decades which have been characterized by citizens' growing exposure to foreign cultures through cross-border information flows, the globalization of mass communication and the role of social media. All of these (and many other) channels may have contributed to reshaping national values/identities as well as trust and affinity towards foreign cultures (see Tabellini, 2008; Giuliano \& Nunn, 2020; Bazzi et al., 2020). ${ }^{4}$ Of course, those changes in bilateral cultural proximity may or may

\footnotetext{
${ }^{1}$ Although the notion of cultural distance has been explicitly defined by scholars, especially in the international business literature $\mathrm{h}$ (see for instance Shenkar (2001)), for simplicity in this paper the terms cultural proximity, cultural affinity and cultural distance will be used interchangeably.

${ }^{2}$ When introducing the dyadic determinants of international migration, Beine et al. (2015) explicitly state "he dyadic factors that influence migration costs can be both time-invariant, such as linguistic and cultural proximity, and time-varying factors." (Beine et al., 2015, p.508).

${ }^{3}$ Also Micro proxies of cultural distance within the World Value Survey and European Value Survey provide a limited time variation.

${ }^{4}$ In this regard, Rapoport et al. (2020) found evidence of cross-country cultural convergence which is clearly at odds with the assumption of stability, but more in line with a convergence hypothesis, where cultural proximity increases over time as a consequence of citizens' exposure to foreign cultures.
} 
not be reciprocated. The symmetric nature of cultural proximity is obviously very difficult to support, especially in the context of international migration. Symmetry in cultural proximity would imply, for instance, that the cultural barriers faced by Moroccans willing to move to France would be the same as those experienced by French migrants going to Morocco. As pointed out by Shenkar (2001), there are no studies showing symmetry in bilateral cultural proximity, nor is there any reason to assume symmetry. The use of the standard proxies of cultural proximity clearly fails to account for these dimensions of cultural relationships and their consequences for the migration decision. This calls for further investigation into the role of culture as a determinant of migration patterns. ${ }^{5}$

In this paper we propose an enriched notion of cultural proximity (henceforth VACP-Time-Varying and Asymmetric Cultural Proximity), which accounts for changes in cultural relationships that may or may not depend on the historical or pre-existing cultural ties. In this conceptual framework, the transfer of norms, practices, identities and social capital through social remittances, as well as exposure to foreign values and behavior, may change how attractive would-be migrants find foreign cultures. This is regardless of pre-existing bilateral cultural ties (see for instance Levitt, 1998). These "shocks" to bilateral cultural proximity affect the migration choice as, for any given country of origin, they alter the distribution of relative cultural affinity towards potential destinations.

To date, this is the first analysis exploring the relationship between cultural proximity and migration, which fully accounts for the time varying and asymmetric nature of VACP. In line with Disdier et al. (2010) and Fiorini et al. (2021), we employ cultural exports as a proxy for revealed cultural preferences. In other words, we assume that the value of bilateral exports of cultural goods reflects affinity towards the destination's (exporter's) culture for the citizens in the country of origin (importer). Our proxy for cultural proximity enters a gravity model of international migration which allows for cultural affinity to vary over time. Theoretically, we postulate that positive variations in cultural proximity, which are reflected by larger volumes of exports of cultural goods, lead to a rise in emigration from importing countries by lowering asymmetric bilateral moving costs between origin and destination.

On the empirical level, relaxing the assumption of stability of cultural proximity implies that migration could in principle affect the evolution of cultural affinity over time. Furthermore, current levels of cultural proximity are likely to be strongly related to historical cultural ties (see Disdier et al., 2010) and previous migration flows, introducing some endogeneity concerns. Our identification strategy addresses potential issues deriving from multiple sources of endogeneity by first instrumenting exports of cultural goods with average bilateral tariffs in the manufacturing sector and the imputed tariff revenues, which are plausibly exogenous with respect to migration. Second, to the best of our knowledge our identification strategy is among the first to utilize a comprehensive set of fixed effects-namely origin*time, destination*time and origin*destination Fes-within a gravity model applied to international migration. This enables us to estimate the impact of time

\footnotetext{
5 Within-country cultural homogeneity is another unrealistic assumption which we do not investigate in this paper because of data limitations.
} 
varying cultural proximity on emigration over and beyond the effect of pre-existing cultural and historical ties. Lastly, in our gravity specification we separately identify the impact of existing diasporas as they simultaneously affect the decision to migrate both through cultural proximity, via the effect of cultural remittances. They also affect decisions to migrate by lowering migration costs through network effects and visa costs or by increasing the probability of non-economic migration through family reunification programs (see Beine et al., 2011).

The results suggest a positive impact on the time variance of cultural proximity on migration choice. In other words, positive changes in cultural proximity foster migration. This finding is robust across different econometric techniques and alternative classifications of cultural products. We also show that a shock in terms of changing cultural proximity has a much stronger effect on culturally distant country pairs and when the long-lasting effect of cultural goods in favoring cross-cultural convergence is accounted for. Taken together, these findings suggest a non-linear effect of cultural proximity on migration over pre-existing cultural ties and the potential (positive) role of trade integration in cultural products in promoting cultural alignment between origin and destination countries. Finally, the analysis not only supports the dynamic dimension of cultural proximity in the context of international migration, but also its asymmetric nature. Our findings reveal that only the time variation of migrant preferences for destination's culture appears to affect emigration decisions.

The rest of the paper is organized as follows. Section 2 presents an overview of the related literature, while Sect. 3 introduces our enriched definition of cultural proximity and describes the theoretical framework. Section 4 outlines the econometric specification as well as the data utilized in the empirical analysis. Section 5 presents the main statistical results. Section 6 concludes.

\section{Related literature}

Our contribution adds to the extensive literature on the determinants of international migration, which uses gravity models as the main empirical workhorse to identify the effect of those origin, destination and dyadic factors affecting migration decisions. Gravity regressions first became very popular in analyzing international trade because they predict bilateral trade between two countries as a function of the respective economic sizes and distance between them. The theoretical foundations of gravity models of trade are widely explored in the literature (see Head and Mayer 2014). However, the interest in gravity models when applied to international migration "has only recently regained momentum because of an enhanced availability of migration data", (Beine et al. 2015). Within this strand of literature, our empirical framework is similar to Ortega and Peri's (2013) framework, which employs a comprehensive set of fixed effects and finds that international migration flows are highly sensitive to income per capita at destination and to bilateral migration policies. As stressed by Bertoli and Moraga (2013), the inclusion of an appropriate specification of origin and destination fixed effects into the gravity setup accounts for the so-called multilateral resistance to migration i.e. for the fact that the choice of a potential migrant to move to a given destination country does not only depend on 
the attractiveness of the destination country relative to the country of origin, "but also on how this relates to the opportunities to move to other destinations" (Bertoli \& Moraga, 2013, p.79). Closer to the subject matter of this paper, Belot and Hatton (2012) show that cultural similarities and physical distance are more relevant drivers of educational selectivity in immigration than wage incentives or bilateral migration policies. A common feature of this strand of literature is that the effect of cultural distance on migration is mostly captured by dummies for common language (official or spoken) and former colonial ties (see Beine et al., 2015). A notable exception is Belot and Ederveen (2012) who capture different aspects of cultural similarities through the use of composite indicators for cultural proximity, along with more standard measures of cultural barriers such as religious and linguistic affinity. Similarly, Guiso et al. (2009) include, among the proxies of cultural similarities, measures of religious, linguistic, genetic and somatic distance. Among these proxies, which are however static and symmetric, linguistic distance has attracted particular attention. In particular, Adserà and Pytlikovà (2015) constructed elaborate indexes of linguistic distance and found that migration rates are higher between countries whose main official languages are closer. They also asserted that linguistic proximity matters less when local linguistic networks are larger.

Even though all of these measures aim to capture multiple dimensions of cultural similarities, an approach which is more in line with a comprehensive notion of "culture" (see Straubhaar, 2002), they implicitly assume that cultural proximity is constant over time and symmetric. In particular, the importance of the role of persistent/ historical cultural traits on various political ramifications (Bazzi et al., 2020; Vertovec, 2011) and economic exchanges (Guiso et al., 2006) is well established in the literature. However, the role of the evolution of cultural proximity over time is often neglected and overlooked. To stress this argument even further, in reviewing the literature on gravity models for international migration, Beine et al. (2015) explicitly stated that cultural proximity is one of the most important "time invariant" dyadic components of bilateral migration costs. This definition of cultural proximity limits the capacity to capture all of the important dimensions of cultural affinity which have already been questioned in the international business, anthropological, sociological and economics literature (see Shenkar, 2001; Li et al. 2017; Felbermayr \& Toubal, 2010; Giuliano \& Nunn, 2020; Fiorini et al. 2021; Tung Verbeke, 2010). In this regard, Felbermayr and Toubal (2010). In this regard, Felbermayr and Toubal (2010) used the voting results of the Eurovision Song Contest (ESC) as a proxy for cultural proximity and found a significant time variation in the ESC scores that were awarded. They also evidenced a sometimes low degree of reciprocity even between countries with seemingly similar cultural attributes. Disdier et al. (2010) were the first to utilize trade in cultural products as a proxy for countries' cultural proximity. They found that countries with similar cultural tastes have more intense trade relationships. Fiorini et al. (2021) combine these two contributions by applying cultural trade to study its impact on FDI. Our analysis employs a similar conceptual framework to study the impact of the time variation of cultural affinity on international migration by using bilateral exports in cultural goods from OECD to sending countries (migrant origins) as a proxy cultural proximity. 
This paper also sheds some light on the role of trade in cultural goods in favoring migration through a progressive cultural alignment between origin and destination countries. We postulate that bilateral cultural exports raise reverse emigration by transferring cultural values, practices, habits, and norms to importing countries, making trading-pairs culturally closer and therefore lowering moving costs of would be emigrants. To date, the literature has mostly focused on the transfer of behavioral and cultural norms as a "migration externality"-i.e. the effect of diaspora networks on cultural integration through the role of social and cultural remittances (Levitt, 1998). For instance, Spilimbergo (2009) found that foreign trained individuals promote democracy in their home countries, but only if foreign education was acquired in a democratic destination. Focusing on Moldova, a former Soviet Republic, Barsbai et al. (2017) show that emigration to democratic countries decreases the share of votes for communist parties in home districts. Rapoport et al. (2020) found that migrants act as vectors of cultural diffusion and bring about cultural convergence through the dissemination of cultural values and norms from host to home countries (i.e., cultural remittances). In this paper we take a different approach and look at the effect on migration of cultural change induced by trade integration of cultural products. This links our paper to the work of Maystre et al. (2014), who show that trade integration leads to cultural convergence, especially for trade in differentiated goods with a higher cultural content. Along similar lines, we argue that cultural exports act as a sort of cultural remittances-as they transfer knowledge and familiarity about cultural values, practices and norms of migrant destinations to importing countries. In line with our hypothesis, the results presented in one of the extensions of the baseline model (Table 7) suggest a long-lasting positive effect of cumulative cultural exports on reverse emigration, which complements previous research on trade-based cultural change and its impact on emigration decisions (e.g. Maystre et al., 2014; Campaniello, 2014).

\section{Cultural proximity and trade in cultural goods}

Numerous empirical studies employed proxies of cultural affinity which overlook its time varying and asymmetric dimensions. For instance, the pioneering work of Belot and Ederveen (2012) employed several refined measures of cultural distance. This included a composite index based on the four Hofstede's cultural dimensions, along with measures of linguistic and religious proximity, to estimate the impact of cultural barriers on international migration. The drawbacks associated with the definition of cultural distance have been brought to the fore in economics and even more prominently in other disciplines such as psychology, anthropology and the international business literature. ${ }^{6}$ In particular, two limitations of this approach stand out, namely the assumption of stability and symmetry, relabelled by Shenkar (2001) as, respectively, the "illusion of stability" and the "illusion of symmetry".

\footnotetext{
${ }^{6}$ See Shenkar (2001), Fiorini et al. (2021), Li et al. (2017), Tung and Verbeke (2010) and Felbermayr and Toubal (2010)
} 
The roots of the dynamic or processual view of cultural relationships that allows for values and practices to be continuously reshaped by social (and economic) interactions, can be traced back to the so-called "Intergroup Contact Theory" (Allport, 1954). The rationale behind the contact hypothesis is that more frequent and intensive contacts between different groups lead to a more tolerant society and improve social relations (also) through a reciprocal transfer of knowledge and information. ${ }^{7}$ The contact hypothesis implicitly relates to a pattern of cultural relationships that evolve over time, although not necessarily in a symmetric fashion. Closer to our purposes, the role played by diaspora networks through social and cultural remittances, for instance, is an example of how higher levels of cross-cultural interactions between host and origin communities can positively affect the perception and the affinity towards foreign cultures over time, through the so-called information or "acculturation" channel (Berry, 1980; Levitt, 1998). The static notion of cultural distance is also challenged by numerous anthropologists and sociologists, who propose definitions of culture that emphasize its dynamic, changing and transformative nature (Vertovec, 2011). While in these fields of research a micro-level approach is regarded as better-suited to study the evolution of cultural relationships, for the purpose of this study a notion of bilateral time-varying cultural proximity can still be introduced at the cross-country level-conditional on the assumption that national cultures share (at least to a certain extent) common cultural traits (see Guiso et al., 2009).

Hereafter, we briefly discuss each limitation in the context of international migration. We provide an alternative and purposefully broader definition of cultural proximity which allows for both time variation and asymmetry in cross country cultural relationships.

Stability The four dimensions identified by Hofstede (2001) measure how far apart two cultures are, as well as other standard proxies of bilateral cultural proximity such as religious and linguistic proximity. These are measured, though, at a single point in time and they are assumed to be constant. However, cultural proximity evolves over time. The cultural affinity towards a specific destination measured at the moment of the decision to migrate may have changed by the time cultures are measured. In other words, the distribution of the destination culture's attractiveness across foreign countries changes over time; it is a function of several factors, including ideas and practices transferred to countries of origin. This variation in cultural proximity affects the migration choice as-for any country of origin-it alters the relative cultural affinity towards potential destinations.

Symmetry The construct of cultural distance obviously requires symmetry: the distance from A to B must be identical to the one from B to A. But this assumption has found no support in the literature. As highlighted by Shenkar (2001), Tung and

\footnotetext{
7 As Allport (1954) in his seminal book pointed out, these contacts can be "direct" or "indirect": the consumption of cultural products, for instance, such as films, books, etc. can indirectly reduce prejudice and get people "closer" through the reduction of cultural distance.
} 
Verbeke (2010) and Li et al. (2017) cultural relationships, which are relevant in the context of international economic exchanges, are far from being symmetric. Furthermore, Fiorini et al. (2021) and Felbermayr and Toubal (2010) found evidence of cultural asymmetry between country pairs. Their evidence points to an important role in the asymmetric dimension of cultural affinity in determining cross-country socioeconomic interactions and calls for a broader notion of cultural proximity capable of reflecting asymmetric affinity between two countries. While the primary focus of this paper is on the role of a specific direction of time-varying cultural proximityi.e. the affinity towards the destination's culture for citizens in the country of origin-in one of the extensions we also analyze and quantify the implications of the asymmetric nature of cultural proximity in the context of international migration.

Our definitionIn line with these approaches, we depart from the construct of cultural distance and propose a workable definition of cultural proximity that relaxes both these assumptions. We assume that members of the same national culture share common cultural traits and have a fairly homogeneous view on the attractiveness of other cultures ( $\mathrm{Li}$ et al. 2017, Brewer \& Brown 1998).

We define cultural proximity as:

$$
V A C P_{i n, t}=f\left(G_{i n}, A_{i n, t}\right)
$$

where $f$ is an increasing function of cultural proximity, $G_{\text {in }}$ denotes the time invariant component of cultural proximity. It stands for pre-existing or historical cultural ties, whose proxies, such as past colonial relationships, linguistic, religious and genetic distance, have been extensively used in the literature to capture the impact of cultural barriers on migration (see Beine et al. 2015). Contrary to the model proposed by Fiorini et al. (2021), $G_{i n}$ may or may not be symmetric. The key assumption here is that the parameter $G_{i n}$ is time invariant, so that $G_{i n}=G_{i n, t} . A_{i n, t}$ denotes the attractiveness of $n$ 's culture for the population in country $i$. $A_{i n, t}$ is time varying and asymmetric, i.e. the identity $A_{i n}=A_{n i}$ may not be verified at any time $t$. The evolution of cultural proximity over time for any country pair depends on the $A_{i n, t}$ term, which may or may not be related to pre-existing cultural ties, i.e. $A_{i n, t}$ could potentially not depend on $G_{i n}$. Indeed, individuals in country $i$ can, in principle, attribute desirable characteristics to the culture of country $n$ independent of any actual similarity between the two cultures. ${ }^{8}$

Building on Disdier et al. (2010) we argue that bilateral trade in cultural goods can be used as a valid proxy for cultural proximity. More precisely, we employ the volume of cultural exports as a measure of "revealed cultural preference"-i..e. an increase in the demand of cultural goods from a given country of (migrant) destination reflects higher preference for the culture of that country. We postulate that positive variations in cultural proximity lead to a rise in emigration from importing

\footnotetext{
8 We are well aware that both dimensions of cultural proximity can be affected by factors that may be related to migration. Diasporas, for instance, can, in principle, be associated to both dimensions of cultural proximity and simultaneously affect the migration choice through a network effect. These endogeneity issues will be addressed in our empirical specification presented in the next section.
} 
countries by lowering asymmetric bilateral moving costs between origin and destination. The positive effect of VACP on migration operates mostly through the reduction of psychological costs and all the moving costs associated with settling in and adjusting to a new cultural environment, which-according to Kennan and Walker (2011) — play a crucial role in emigration decisions. ${ }^{9}$

Figure 1 plots the relationship between bilateral emigration rates from the importer country and the share of cultural exports from the country of destination. Our conjecture is that the correlation between migration and cultural exports is stronger because cultural preferences plausibly affect the utility derived from the purchase of cultural goods relatively more than their non-cultural counterparts. In other words, cultural preferences are better reflected in the purchase of cultural goods. In line with our hypothesis, Fig. 1 shows a positive relationship, which we attribute to the better capacity of cultural products to capture cross country cultural attractiveness.

The time-varying and asymmetric nature of trade flows allows us to these dimensions of bilateral cultural proximity. Specifically, given the purpose of this paper we are interested in cultural exports from destination $n$ to origin $i$ which proxies for $A_{i n, t}$, i.e. the attractiveness of $n$ 's culture for individuals in $i$ at time $t .{ }^{10}$ The underlying theoretical mechanism is in line with the approach of Guiso et al. (2009). This is because changes in cultural proximity over time are reflected through variation in the demand for cultural goods produced in foreign countries. The recent case of the Korean Wave (Hallyu) is a good example of how the appreciation and penetration of the Korean culture in foreign countries is reflected in the rise of exports of cultural products, such as TV soap operas and pop music records (K-pop). Interestingly, the rise in popularity of the Korean culture around the world is not rooted in ancestral cultural traits but instead can be associated with a cultural shock (Fiorini et al. 2021). Scholars have started to identify a connection between the Korean Wave and a rise in economic exchanges. Box 1 in the "Appendix" highlights the case of the Korean Wave and illustrates its relationships with emigration decisions from importing countries.

\footnotetext{
${ }^{9}$ Kenan and Walker (2011) estimate that psychological migration costs account for about two thirds of average annual income, or about 23,000\$ per year in monetary terms. Kenan and Walker (2011) do not label these costs as specifically "'psychological"; rather their estimates are related to a bias in favor of the home location. This implies that, for instance, potential migrants will not move anywhere else unless they earn $\$ 23,000$ more than what they earn now. Since these estimates apply to internal migration within a large country where language, culture and political rights are broadly similar, it may be seen as the lower limit for the psychological cost of international migration.

${ }^{10}$ In "Appendix A1" we show that there is an empirical relationship between trade in cultural goods and the symmetric-time-invariant proxies of $G_{i n}$, indicating that attractiveness is strongly correlated with similarity. However, investigating the link between the dynamic and the static component of cultural affinity is beyond the purpose of this paper: the scope of our contribution is to add a time-varying and asymmetric dimension to bilateral cultural affinity and to test to what extent cultural proximity towards a destination affects the migration choice over and above pre-existing cultural ties.
} 


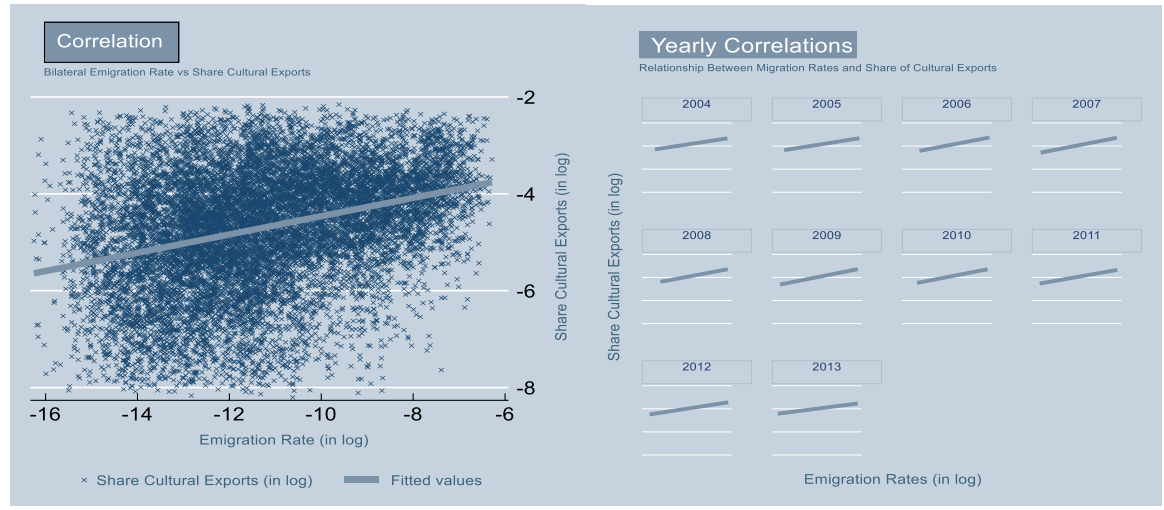

Fig. 1 Log-log relationship between the bilateral share of cultural exports at $t-1$ from the country of destination and the migration rate from the country of origin at time t. The right panel reports yearly correlations while the left panel shows the correspondent fitted line for the pooled sample. The share is constructed as bilateral cultural exports over aggregate bilateral exports. We exclude from the sample potential outlier observations as the information that belongs to the first and the last 3 percentiles of the distributions are dropped

\section{Model and econometric specification}

\subsection{Econometric specification}

The econometric model can be expressed as:of bilateral cultural flows

$$
\ln \left(M_{i n, t}\right)=S_{i, t}+S_{n, t}+S_{i n}+\ln \left(X_{c u l t}{ }_{n i, t}\right)+\ln \left(Q_{i n, t}\right)+u_{\mathrm{in,t}}
$$

where $X_{\text {cult }}$ in,t is the bilateral exports of cultural goods from the destination country $n$ to the country of origin $i$ at time $t . Q_{i n, t}$ is the bilateral stocks of emigrants born in $i$ and resident in $n$ at time $t$; it is included to proxy for migrant networks (diaspora) that reduce the cost of moving to destination country $n$. Networks may also be an indicator of cultural proximity because larger immigrant communities are likely to be associated with common cultural characteristics between hosting and origin countries. They can also be agents of change by transferring information. Our econometric specification is rich enough to be consistent with more general distributional assumptions of the error term $u_{\text {in,t }}$ (see Beine et al., 2015). The inclusion of $\mathrm{S}_{\mathrm{i}, \mathrm{t}}$ and $\mathrm{S}_{\mathrm{n}, \mathrm{t}}$ - which are respectively, origin-year and destination-year fixed effectscompletely absorbs the impact of monadic (country-specific) determinants of international migration, such as conflicts as well as demographic, socio-political and environmental factors. In addition, these fixed effects allow us to account for the socalled multilateral resistance to migration. Put in other terms, it is possible to capture the impact of the influence that the attractiveness of possible other destinations 
exerts on the decision to migrate to a given destination. ${ }^{11}$ In particular, the variable $\mathrm{S}_{\mathrm{n}, \mathrm{t}}$ absorbs the average time-varying tightness of migration entry laws in every destination, which was found to have a significantly negative impact on immigration flows by Ortega and Peri (2013). In order to better isolate the time varying impact of cultural affinity on emigration we also include asymmetric origin-destination fixed effects $S_{\text {in }}$ which absorb all bilateral specific factors affecting migration. For the purpose of this paper the inclusion of $S_{i n}$ is important for two main reasons:

- $S_{\text {in }}$ allows us to identify the effect of cultural proximity over and above symmetric and pre-determined bilateral cultural ties. The current level of cultural proximity between country-pairs is likely to be related to the "historical" component of their cultural relationship (see "Appendix A1"). This may not be entirely captured by the time invariant proxies of $G_{i n}$ commonly used in the literature to control for moving costs, such as colonial ties or linguistic, religious and geographical distance. This implies that failing to account for initial conditions may lead to biased estimates due to omitted variable bias (see Baier \& Bergstrand, 2007). $S_{\text {in }}$ completely absorbs the cross-sectional variability in our sample. Hence, we are able to focus on the impact of the time contingent cultural factors alone.

- The inclusion of dyadic fixed effects restores the cross-sectional independence of the error terms (see Bertoli \& Moraga, 2015). Indeed, if we define $b(i)$ as a nest of countries $i$ characterized by similar levels of cultural proximity with $n$, a bilateral shock between $n$ and $i$ may introduce a correlation in the stochastic component of Eq. (6). For instance, the impact of a more restrictive visa policy towards Moroccans in the UK will affect the relative attractiveness of other potential destinations which we realistically assume to be highly dependent upon cultural proximity between Morocco and third countries (i.e. on whether or not they belong to the same nest $b(i)$ ). In other words, if the unobserved components that create interdependencies across cross-sections within nests are correlated with the included regressors, the OLS estimator will be biased and inconsistent. Bertoli and Moraga (2015) restored the cross-sectional independence of the error terms through the inclusion of origin-nest dummies. Similarly, this paper proposes a richer analysis in which we generate a nest for each country-pair through $S_{i n}$, alleviating potential estimation problems deriving from an incorrect specification.

\subsection{Endogeneity concerns}

An issue arising when estimating Eq. (2) is the potential endogeneity of trade in cultural goods. The main concern is whether this covariate is correlated with an unobserved component. In addition, since migration and trade are likely to be closely connected, the correlation between the two variables might be due to, other than the omitted variables we do not control for, reverse causality. This means that migrants

\footnotetext{
11 Using migration rates or migration flows as dependent variable in our econometric specification will leave the results unaffected. The inclusion of origin*time fixed effects in Eq. (2) makes the distinction between flows and rates irrelevant, as the set of dummies completely absorb the effect of origin specific variables, including population at the origin-which is the denominator of bilateral emigration rates.
} 
may promote trade with their country of origin as well as cultural convergence (see for instance Gould, 1994; Rapoport et al., 2020). ${ }^{12}$

Our analysis aims to address the endogeneity issue in four ways:

- We include a comprehensive set of fixed effects to control for unobserved dyadic time-invariant factors and unobserved time-varying country-specific factors that drive both cultural proximity and migration flows. We are able to properly identify the relationship between cultural exports and emigration through the inclusion of country-pair fixed effects. To the best of our knowledge, this is among the first contributions to apply a gravity model to international migration which combines a full set of destination*year, origin*year and destination*origin FEs in the spirit of Baier and Bergstrand (2007) and Disdier et al. (2010). Finally, to further alleviate the problems associated with omitted variable bias we include bilateral imports as well as non-cultural exports in the specification (see Table 8), which partially control for time varying bilateral contacts between destination and origin.

- In line with Aleksynska and Peri (2014), we use the fact that the value of bilateral trade labeled as "cultural" according to UNCTAD classification, Xcult $t_{\mathrm{ni}, \mathrm{t}}$, is equal to the aggregate bilateral trade $X_{\text {ni,t }}$ multiplied by the correspondent share of bilateral cultural flows $\alpha_{\mathrm{ni}, \mathrm{t}}$. Specifically, $X c u l t_{\mathrm{ni}, \mathrm{t}}=\alpha_{\mathrm{ni}, \mathrm{t}} * X_{\mathrm{ni}, \mathrm{t}}$. Hence, by taking logs and using log properties, we can separate the effect into two terms: $\ln \left(X_{\text {cult }} t_{\mathrm{ni}, \mathrm{t}}\right)=\ln \left(X_{\mathrm{ni, \textrm {t }}}\right)+\ln \left(\alpha_{\mathrm{ni}, \mathrm{t}}\right)$. The advantage of this type of specification is that it builds on previous studies examining the trade-migration nexus, which normally included the log of aggregate trade as a dependent variable or a dyadic control in a gravity setup, depending on the direction of causation. ${ }^{13}$ Second, in our pooled OLS setting, aggregate bilateral trade absorbs common factors that affect aggregate trade and migration. This allows us to isolate and disentangle the extra impact of cultural products on migration flows within the same specification.

- The variable of interest—namely exports of cultural goods-is predetermined with respect to emigration flows, which is likely to (at least) attenuate the issue of reverse causality. The same "lagged approach" applies to other controls such as the impact of immigrant stocks $\left(Q_{i n, t}\right)$, in line with the analysis of Beine and Parsons (2015). ${ }^{14}$

\footnotetext{
12 Another potential source of endogeneity is measurement error which is addressed in Sect. 5.2.

13 See Campaniello (2014), for the export effect on migration; see Aleksynska and Peri (2014), Girma and $\mathrm{Yu}$ (2002) and Gould (1994) for the other direction of causation.

14 As pointed out by Beine and Parsons (2015) another econometric issue in this gravity setup is the potential endogeneity of the network effect, which is proxied by the stocks of migrants born in $i$ and resident in $n$. The network effect is predetermined with respect to migration flows, so the reverse causality argument should not be an important issue here. In addition, Beine et al. (2011) and Beine and Parsons (2015) address the potential endogeneity of bilateral stocks of emigrants with an IV strategy and by augmenting the gravity specification with variables which are both correlated with the error term and with the stocks of migrants, respectively. Reassuringly, their findings confirm the exogeneity of their predetermined network effect.
} 
- We propose an IV strategy where we instrument the flows of exports in cultural goods with the average bilateral tariffs in the manufacturing sector (source WITS, World Bank), which are applied by the importer and the corresponding imputed tariff revenues. As far as we know, we are the first to implement an IV strategy to study the relationship between cultural proximity and migration flows. ${ }^{15}$ Similarly to Campaniello (2014), the identification strategy in this paper hinges upon the assumption that bilateral tariffs do not depend on migratory flows. In other words, we postulate that governments set the level of tariffs to affect only trade flows, but not migration inflows. The first stage statistics along with Fig. 2 provide some empirical support to this statement, as the under identification, the reduced form and weak identification tests conducted and presented in Table 4 all point to the strength and the validity of the instruments. Hence, we plausibly assume the relationship between tariffs and migration as indirect i.e. running from the tariff-related instruments through the endogenous variable.

\subsection{Data}

The analysis uses data on 30 OECD countries of destination and on 185 countries of origin in the period 2004-2013. ${ }^{16}$ The sample composition is similar to the work of Adserà and Pytlikovà (2015). It is more comprehensive than other contributions that focus on the impact of cultural proximity on migration decisions, such as Belot and Ederveen (2012). The complete list, along with a short description of the variables employed in the statistical analysis, is presented in "Appendix A2", while the summary statistics of the main variables (including instruments) are outlined in Table 1.

Our main variable of interest is trade in cultural goods. Trade data are from the BACI dataset of CEPII, which provides the bilateral values of exports in the HS 6-digit product disaggregation, for more than 200 countries since 1995. A crucial issue for our analysis concerns the definition of "cultural goods". In line with the definitions provided by UNESCO and UNCTAD we define cultural products as those goods "conveying ideas, symbols and ways of life to those who consume them (some of which may be subject to copyrights), and whose production requires some input of human creativity" (UNESCO 2009; UNCTAD, 2010). At the empirical level, we use the classification of cultural/creative products proposed by UNCTAD. "Appendix A3" provides the reasons why we prefer this classification as the main workhorse for our empirical analysis, while in Table 13 we list all of the domains and product codes labelled as cultural/creative according to both UNCTAD and UNESCO classification.

In the IV analysis we instrument exports of cultural products with the average bilateral tariffs applied in the manufacturing sector and the imputed tariff revenues from cultural trade. The average of bilateral tariffs is obtained as the simple mean

\footnotetext{
15 Average Tariffs applied by EU countries have already been used as an instrument to address the potential endogeneity of bilateral aggregate trade flows in its relationship with migrants' stocks by Campaniello (2014).

16 The sample refers to the specification with the full set of fixed effects (Column 3 in Table 2).
} 


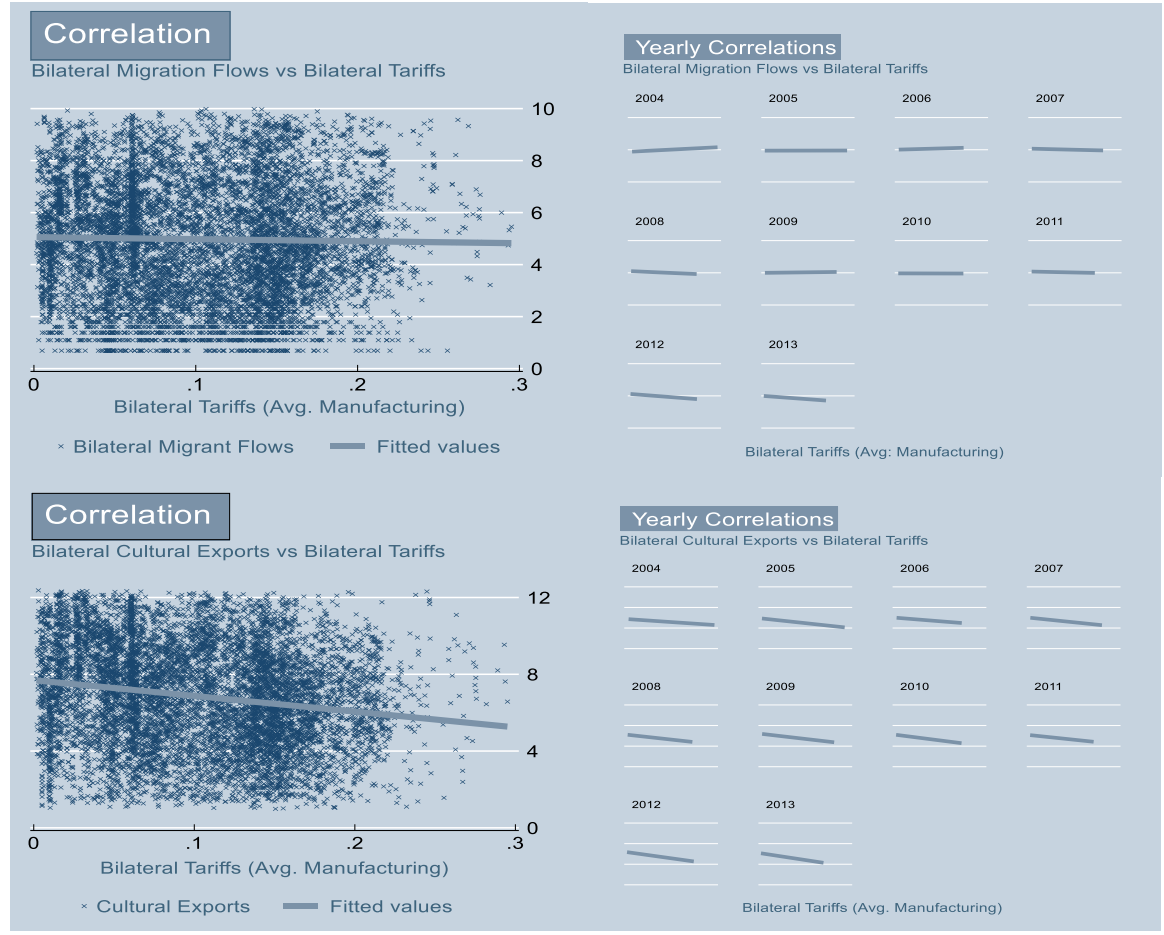

Fig. 2 Correlation between average bilateral tariffs at time t-1 in the manufacturing (in \%) and a $\log$ of cultural exports at time t-1 (bottom panel) and $\mathbf{b} \log$ of bilateral migration outflows at time $\mathrm{t}$ (upper panel). The right panels report yearly correlations while the left panels show the correspondent fitted line for the pooled sample. We exclude from the sample potential outlier observations as the information that belongs to the first and the last 3 percentiles of the distributions are dropped. The correlations refer to the smaller IV sample which includes 148 countries of origin and 22 countries of destination for the period 2004-2013

across EORA manufacturing sectors. ${ }^{17}$ As for the rest of the variables employed in the statistical analysis, the migration flows and migration stocks are from the OECD's International Migration database. ${ }^{18}$ Since we are interested in the determinants of migration decisions we use the inflows of foreign population by nationality in a given year as the dependent variable. This definition implies that we are including "all foreign-born (or in some cases foreign nationals) who come to the country to reside there and not for temporary tourism, study, or business reasons" (Ortega Peri, 2013). We include the stocks of bilateral immigrants who are resident

\footnotetext{
17 The list of EORA manufacturing sectors include: Electrical and Machinery, Food \& Beverages, Metal Products, Other Manufacturing, Petroleum, Chemical and Non-Metallic, Textiles and Wearing Apparel, Transport Equipment, Wood and Paper.

18 We are well aware of the limitations of the OECD International Migration Database regarding the comparability across OECD destinations (see Ortega and Peri (2013) and Mayda (2010) for a discussion). While these inconsistencies can make a pure cross-country comparison inaccurate, it is reasonable to think that changes over time can be compared.
} 
Table 1 Summary statistics

\begin{tabular}{|c|c|c|c|c|c|c|}
\hline \multirow{2}{*}{$\begin{array}{l}\text { Sample } \\
\text { Variable }\end{array}$} & \multicolumn{3}{|l|}{ Full } & \multicolumn{3}{|l|}{ IV } \\
\hline & Mean & Median & $\mathrm{SD}$ & Mean & Median & SD \\
\hline $\ln \left(\mathrm{EM}_{\mathrm{in}, \mathrm{t}}\right)$ & 5.077 & 5.056 & 2.492 & 4.967 & 4.905 & 2.503 \\
\hline $\ln \left(\right.$ Xcult $\left._{n i, t-1}\right)$ & 7.210 & 7.304 & 3.180 & 6.902 & 6.953 & 2.984 \\
\hline $\ln \left(Q_{\mathrm{in}, \mathrm{t}-1}\right)$ & 7.824 & 7.773 & 2.622 & 7.799 & 7.679 & 2.642 \\
\hline $\ln \left(\right.$ dist $\left._{\text {in }}\right)$ & 8.433 & 8.674 & 0.912 & - & - & - \\
\hline Colony $_{\text {in }}$ & 0.047 & 0 & 0.212 & - & - & - \\
\hline Lang $_{\text {in }}$ & 0.120 & 0 & 0.325 & - & - & - \\
\hline Comleg $_{\text {in }}$ & 0.222 & 0 & 0.415 & - & - & - \\
\hline AvgTariffs $_{\mathrm{in}, t-1}$ & - & - & - & 0.104 & 0.101 & 0.066 \\
\hline $\ln \left(\right.$ TariffsRev $\left._{\mathrm{ni}, t-1}\right)$ & - & - & - & 4.284 & 4.322 & 2.967 \\
\hline Obs & 15,062 & 15,062 & 15,062 & 10,369 & 10,369 & 10,369 \\
\hline
\end{tabular}

Data on Bilateral Trade are expressed in thousands of US Current Dollars. Data on average tariffs are expressed in $\%$ and calculated as sample mean over the EORA manufacturing sectors. The statistics reported in Columns (1-3) refer to the baseline sample of Table 2, while Columns (4-6) report the correspondent summary statistics of the IV sample (Table 4)

in the countries of destination among the covariates, since they capture the role of networks in shaping international migration flows (see Beine et al., 2015). Standard Proxies for migration costs, such as weighted distance, common language, former colonial relationships, common legal origin, are from CEPII, while GDP per capita in PPP Constant US dollars are from the World Bank. More refined measures of pre-determined cultural proximity such as linguistic and genetic distance are from Adserà and Pytlikovà (2015) and Melitz and Toubal (2014).

\section{Results}

\subsection{Benchmark estimates}

The estimates of Eq. (2) are presented in Table 2. We progressively allow for lower degrees of variability across specifications in our identification data by gradually augmenting the number of fixed effects. Column (1) includes a reduced set of origin-year and destination dummies which capture time-varying factors at origin and time-invariant factors at destination, including unobserved heterogeneity in cultural traits between migrants and non-migrants. This specification is very close to the predictions of the model proposed by Ortega and Peri (2013). Our parameter of interest, the coefficient of $\ln \left(X_{c u l t} t_{\text {ni,t-1 }}\right)$, suggests a significantly positive relationship between proximity of country $i$ towards country $n$ 's culture and bilateral emigration from origin $i$ to destination $n$. All of the gravity controls are significant and have the expected sign. Income per capita at destination is confirmed as an important driver of migration flows, while the network effect is positive and its magnitude is in line with previous studies (see Beine et al. 2011; Beine \& Parsons, 2015; Bertoli 
Table 2 Benchmark results: impact of cultural exports on the emigration rate

\begin{tabular}{|c|c|c|c|c|c|}
\hline Dependent Var. & $\begin{array}{l}(1) \\
\text { OLS } \\
\ln \left(\mathrm{EM}_{\mathrm{in}, \mathrm{t}}\right)\end{array}$ & $\begin{array}{l}(2) \\
\text { OLS } \\
\ln \left(\mathrm{EM}_{\mathrm{in}, \mathrm{t}}\right)\end{array}$ & $\begin{array}{l}(3) \\
\text { OLS } \\
\ln \left(\mathrm{EM}_{\mathrm{in}, \mathrm{t}}\right)\end{array}$ & $\begin{array}{l}(4) \\
\text { OLS } \\
\ln \left(\mathrm{EM}_{\mathrm{in}, \mathrm{t}}\right)\end{array}$ & $\begin{array}{l}(5) \\
\text { OLS } \\
\ln \left(\mathrm{EM}_{\mathrm{in}, \mathrm{t}}\right)\end{array}$ \\
\hline $\ln \left(\right.$ Xcult $\left._{n i, t-1}\right)$ & $\begin{array}{l}0.072 * * * \\
(6.56)\end{array}$ & $\begin{array}{l}0.072 * * * \\
(6.56)\end{array}$ & $\begin{array}{l}0.013 * * \\
(2.26)\end{array}$ & $\begin{array}{l}0.012 * * \\
(2.19)\end{array}$ & \\
\hline $\ln \left(\right.$ XNoncult $\left._{n i, t-1}\right)$ & & & & $\begin{array}{l}0.017 \\
(1.29)\end{array}$ & \\
\hline $\ln \left(\alpha_{\mathrm{ni}, \mathrm{t}-1}\right)$ & & & & & $\begin{array}{l}0.012^{* *} \\
(2.16)\end{array}$ \\
\hline $\ln \left(X_{n i, t-1}\right)$ & & & & & $\begin{array}{l}0.028^{* *} \\
(2.01)\end{array}$ \\
\hline $\ln \left(\mathrm{Q}_{\mathrm{in}, \mathrm{t}-1}\right)$ & $\begin{array}{l}0.553^{* * *} \\
(13.01)\end{array}$ & $\begin{array}{l}0.553^{* * *} \\
(12.86)\end{array}$ & $\begin{array}{l}0.092 * * * \\
(3.26)\end{array}$ & $\begin{array}{l}0.093 * * * \\
(3.29)\end{array}$ & $\begin{array}{l}0.098 * * * \\
(3.28)\end{array}$ \\
\hline $\ln \left(\right.$ dist $\left._{\text {in }}\right)$ & $\begin{array}{l}-0.484 * * * \\
(-9.67)\end{array}$ & $\begin{array}{l}-0.489 * * * \\
(-9.72)\end{array}$ & & & \\
\hline Colony $_{\text {in }}$ & $\begin{array}{l}0.369 * * * \\
(2.90)\end{array}$ & $\begin{array}{l}0.356^{* * * *} \\
(2.77)\end{array}$ & & & \\
\hline Lang $_{\text {in }}$ & $\begin{array}{l}0.391 * * * \\
(4.79)\end{array}$ & $\begin{array}{l}0.399 * * \\
(4.64)\end{array}$ & & & \\
\hline Comleg $_{\text {in }}$ & $\begin{array}{l}0.094 * \\
(1.67)\end{array}$ & $\begin{array}{l}0.091 \\
(1.62)\end{array}$ & & & \\
\hline $\ln \left(\mathrm{GDPpc}_{\mathrm{n}, \mathrm{t}}\right)$ & $\begin{array}{l}1.103 * * * \\
(2.87)\end{array}$ & & & & \\
\hline$S_{i, n}$ & & & $X$ & $X$ & $\mathrm{X}$ \\
\hline$S_{n, t}$ & & $\mathrm{X}$ & $X$ & $X$ & $\mathrm{X}$ \\
\hline$S_{i, t}$ & $\mathrm{X}$ & $\mathrm{X}$ & $\mathrm{X}$ & $\mathrm{X}$ & $\mathrm{X}$ \\
\hline$S_{n}$ & $X$ & & & & \\
\hline$S_{t}$ & $\mathrm{X}$ & & & & \\
\hline$N$ & 15,062 & 15,062 & 15,062 & 15,062 & 15,062 \\
\hline Adj. $R-s q$ & 0.90 & 0.90 & 0.98 & 0.98 & 0.98 \\
\hline
\end{tabular}

$t$ statistics in parentheses; $* p<0.10, * * p<0.05, * * * p<0.01$. Standard Errors are clustered by country pair. $\mathrm{EM}_{\mathrm{in}}$ is the annual bilateral flows of emigrants from the importing country $i$ to the exporting country $n$. Xcult $t_{n i}$ is the volume of exports of cultural goods from the migrant destination $\mathrm{n}$ (exporter) to the country of origin of migration i (importer). From the third to the fifth columns the model includes also country-pair FEs and all the covariates that are time invariant are automatically dropped. The OLS estimates are obtained with the STATA command reghdfe provided by Sergio Correia which allows for the inclusion of high dimensional fixed effects. The dependent variable in the OLS specification is the log of the bilateral emigration rate; Cultural products are defined according to the HSO2 classification of creative goods provided by UNCTAD

\& Fernandez-Huertas Moraga, 2015). This result corroborates with the consensus in the literature on diasporas as the most important dyadic determinants of migration flows. Controlling for heterogeneity at destination-year level leaves our results 
substantially unaffected. The inclusion of destination-year fixed effects in Column (2), meanwhile, does not alter the coefficients of any of the dyadic explanatory variables.

These two specifications, however, do not tell us whether the effect of cultural proximity on the migration choice is only driven by historical and pre-existing cultural similarities. In other words, we cannot detect whether the evolution of cultural relationships over time plays a role in affecting migration decisions, as the time invariant component of cultural proximity, $G_{i n}$, may act as confounding factor for the impact of $A_{i n, t}$. To address this issue, we include dyadic fixed effects $\mathrm{S}_{\text {in }}$ which control for all time invariant bilateral factors, such as geographic barriers and pre-existing cultural ties. The results reported in Column (3) suggest that the time-varying determinants of migration remain significant despite the loss of identification power due to the large number of fixed effects introduced. In particular, the network coefficient retains the positive sign, but it lowers considerably in terms of magnitude, with a semi-elasticity of approximately 0.09 and statistically significance at the $1 \%$ level. More importantly for our purposes, the evolution of bilateral cultural proximity over time emerges as a significant driver of international migration: a "positive shock" in cultural proximity represented by an increase in cultural exports by $10 \%$ leads to a $0.13 \%$ increase in the reverse bilateral migration rate after controlling for all the dyadic and time invariant factors affecting migration decisions. In other words, cultural attractiveness affects the migration choice over and above the pre-existing cultural similarities. The effect is not only statistically significant, but also quantitatively relevant. A simple back-of-the-envelope calculation shows that moving from the sample median to the 75th percentile of cultural exports, leads to around 165 more migrants per dyad. This roughly corresponds to an additional 29,343 international immigrants per destination, which is about $16 \%$ of the average number of migrants per destination in 2010. This sheds some light on the importance of accounting for the evolution of cross-country cultural relationships and their linkages with recent migration phenomena. For instance, the $41 \%$ increase in international migrants from 2000 to 2014 may at least partially be explained by a trend of cultural convergence associated with globalization. ${ }^{19}$ Our results are consistent with such an interpretation. The last two Columns of Table 2 enrich the gravity specification by, respectively, adding non-cultural exports (Column 4) as additional control and decomposing exports in cultural products into the share of cultural products and total bilateral exports (Column 5). The findings suggest that only the time-variation of exports is positively associated with emigration flows, with the share of cultural exports having an impact above and beyond the correspondent aggregate flows.

The results hold when estimating the gravity equation with PPML (Table 3), which provides consistent estimates in the presence of heteroscedasticity and performs well when the dependent variable has a relatively large share of zeros (Santos Silva \& Tenreyro, 2006, 2011; Bertoli \& Moraga 2015). In our sample the share of

19 Source: UN data. 
Table 3 Robustness check: alternative estimators

\begin{tabular}{|c|c|c|c|c|c|c|}
\hline $\begin{array}{l}\text { Estimator } \\
\text { Dependent Var. }\end{array}$ & $\begin{array}{l}(1) \\
\text { PPML } \\
\mathrm{EM}_{\mathrm{in}, \mathrm{t}}\end{array}$ & $\begin{array}{l}(2) \\
\text { PPML } \\
\mathrm{EM}_{\mathrm{in}, \mathrm{t}}\end{array}$ & $\begin{array}{l}(3) \\
\text { PPML } \\
\text { EM }_{\mathrm{in}, \mathrm{t}}\end{array}$ & $\begin{array}{l}(4) \\
\text { PPML } \\
E_{i n, t}\end{array}$ & $\begin{array}{l}(5) \\
\text { EK Tobit } \\
\ln \left(\mathrm{EM}_{\mathrm{in}, \mathrm{t}}\right)\end{array}$ & $\begin{array}{l}\text { (6) } \\
\text { GPML } \\
\mathrm{EM}_{\mathrm{in,t}}\end{array}$ \\
\hline $\ln \left(\right.$ Xcult $\left._{n i, t-1}\right)$ & $\begin{array}{l}0.037 \\
(1.53)\end{array}$ & $\begin{array}{l}0.038 \\
(1.58)\end{array}$ & $\begin{array}{l}0.044 * * * * \\
(2.62)\end{array}$ & & $\begin{array}{l}0.095 * * * \\
(6.12)\end{array}$ & $\begin{array}{l}0.0874 * * * \\
(8.66)\end{array}$ \\
\hline $\ln \left(\alpha_{\mathrm{ni}, \mathrm{t}-1}\right)$ & & & & $\begin{array}{l}0.049 * * \\
(2.84)\end{array}$ & & \\
\hline $\ln \left(X_{n i, t-1}\right)$ & & & & $\begin{array}{l}-0.008 \\
(-0.24)\end{array}$ & & \\
\hline $\ln \left(\mathrm{Q}_{\mathrm{in}, \mathrm{t}-1}\right)$ & $\begin{array}{l}0.663^{* * *} \\
(13.37)\end{array}$ & $\begin{array}{l}0.669 * * * \\
(16.26)\end{array}$ & $\begin{array}{l}0.073 * \\
(1.74)\end{array}$ & $\begin{array}{l}0.072 * \\
(1.74)\end{array}$ & $\begin{array}{l}0.569 * * *) \\
(13.37)\end{array}$ & $\begin{array}{l}0.528 * * *) \\
(19.47)\end{array}$ \\
\hline $\ln \left(\right.$ dist $\left._{\text {in }}\right)$ & $\begin{array}{l}-0.405^{* * *} \\
(-5.31)\end{array}$ & $\begin{array}{l}-0.396 * * * \\
(-5.40)\end{array}$ & & & $\begin{array}{l}-0.396^{* * *} \\
(-6.67)\end{array}$ & $\begin{array}{l}-0.508 * * * \\
(-11.45)\end{array}$ \\
\hline Colony $_{\text {in }}$ & $\begin{array}{l}0.196^{*} \\
(1.74)\end{array}$ & $\begin{array}{l}0.186^{*} \\
(1.69)\end{array}$ & & & $\begin{array}{l}0.596^{* *} \\
(2.54)\end{array}$ & $\begin{array}{l}0.535 * * * \\
(4.72)\end{array}$ \\
\hline Lang $_{\text {in }}$ & $\begin{array}{l}0.127 \\
(1.21)\end{array}$ & $\begin{array}{l}0.132 \\
(1.23)\end{array}$ & & & $\begin{array}{l}0.360^{* * * *} \\
(3.26)\end{array}$ & $\begin{array}{l}0.404 * * * \\
(5.21)\end{array}$ \\
\hline Comleg $_{\text {in }}$ & $\begin{array}{l}0.245^{* *} \\
(2.28)\end{array}$ & $\begin{array}{l}0.234 * * \\
(2.33)\end{array}$ & & & $\begin{array}{l}0.164 * * * \\
(2.10)\end{array}$ & $\begin{array}{l}0.218 * * * \\
(4.50)\end{array}$ \\
\hline $\ln \left(\mathrm{GDPpc}_{\mathrm{n}, \mathrm{t}}\right)$ & $\begin{array}{l}8.129 * * * \\
(11.29)\end{array}$ & & & & $\begin{array}{l}1.157 * * * \\
(16.77)\end{array}$ & $\begin{array}{l}1.389 * * * \\
(3.89)\end{array}$ \\
\hline$S_{i, n}$ & & $X$ & $\mathrm{X}$ & $\mathrm{X}$ & & \\
\hline$S_{n, t}$ & & $X$ & $\mathrm{X}$ & $\mathrm{X}$ & & \\
\hline$S_{i, t}$ & $\mathrm{X}$ & & $\mathrm{X}$ & $\mathrm{X}$ & $X$ & $X$ \\
\hline$S_{n}$ & $X$ & & & & $\mathrm{X}$ & $\mathrm{X}$ \\
\hline$S_{t}$ & $\mathrm{X}$ & & & & $X$ & $X$ \\
\hline$N$ & 16,732 & 16,360 & 16,360 & 16,360 & 16,732 & 16,732 \\
\hline Adj. $R-s q$ & 0.90 & 0.94 & 0.98 & 0.99 & 0.990 & 0.91 \\
\hline
\end{tabular}

$t$ statistics in parentheses; $* p<0.10, * * p<0.05, * * * p<0.01$. Standard Errors are clustered by country pair. $\mathrm{EM}_{\mathrm{in}, \mathrm{t}}$ is the annual bilateral flows of emigrants from the importing country $i$ to the exporting country $n$. Xcult $t_{n i}$ is the volume of exports of cultural goods from the migrant destination $\mathrm{n}$ (exporter) to the country of origin of migration i (importer). The PPML estimates are obtained with the STATA command ppml_panel_sg provided by Thomas Zylkin (see Larch et al. 2019 for more information on this STATA command) The observations which belong to groups with all zeros or missing values are automatically dropped.

zeros is rather small, it represents only $6 \%$ of the observations. ${ }^{20}$ Despite some discrepancies in terms of magnitude with respect to the OLS counterparts, the PPML coefficients shown in Table 3 generally have the expected sign. More importantly,

\footnotetext{
${ }^{20}$ In the OECD International Migration Database missing values cannot be treated as zeros. While missing values are indicated by empty cells, zero values are indicated with 0 . The missing information means data are not available (either not provided by the country, or not available at all). Zeros correspond either to actual zero flows or rather very small flows between country-pairs (see Mayda, 2010). Hence, missing observations in the migration dataset were dropped out of the sample, whereas zeroes are automatically not accounted for in the regressions when estimating the log-linear model, and included in the Poisson PML regression.
} 
in line with our hypothesis, the impact of bilateral exports on migration seems to be predominantly driven by flows of cultural products. To further test the validity of our results, we estimate the gravity model with alternative econometric techniques such as Gamma PML and EK Tobit (Columns 5-6) which accounts for the zero migration flows. Although we cannot compare the performance of these estimators with high dimensional fixed effects, we find it reassuring that the estimates are in line with the results presented in Table $2 .^{21}$

The results presented in Tables 2 and 3 are consistent with different sets of fixed effects and across econometric techniques. However, the reported estimates may still be biased because of reverse causality. To further address the potential endogeneity of trade in cultural goods we instrument $\ln \left(\right.$ Xcult $\left._{n i, t}\right)$ with the average bilateral tariffs in the manufacturing sector applied by the importer and the correspondent imputed tariff revenues (Table 4). Our hypothesis is that governments set the level of tariffs to affect only trade flows, but not migration inflows i.e. we assume that both tariffrelated instruments affect migration indirectly i.e. only through their direct effect on the endogenous variable. Figure 2 provides some empirical support to this conjecture, as the average bilateral tariffs in manufacturing appear to be very weakly correlated to average migration flows.

The sample size for this IV exercise is reduced due to the tariffs dataset which does not provide information on all the country pairs included in our OLS sample. ${ }^{22}$ Table 4 reports the IV results. As expected, both the average bilateral tariffs and the imputed tariff revenues have the expected sign and are strong predictor of exports of cultural products. The Kleibergen-Paap F statistic of the excluded instruments is way above the conventional level and indicates that the instruments are well identified. Then we use the Hansen J-statistic to test the exogeneity and we find a p-value equal to 0.46 , which points to the validity of our set of IVs. The reduced form in Column (3) suggests a direct relationship between the instruments and the dependent variable. By combining the first stage with the reduced form results (Columns 2-3) we can cautiously conclude that the effect of both instruments on the dependent variable runs through the endogenous variable. Of course, bilateral tariffs in the manufacturing sector are also related with non-cultural trade flows. This relationship might weaken the validity of our set of instruments if non-cultural trade is related with emigration flows and not accounted for in our model (Eq. 2). To address this issue, we perform the IV analysis by including non-cultural exports as additional control in our specification (Columns 4-6). The statistics suggest that while the time-variation of non-cultural exports is correlated with cultural trade flows (Column 4), it does not significantly affect emigration from importing countries (Column 5). The latter

\footnotetext{
21 The EK Tobit approach in particular-according to Head and Mayer's (2014) Monte-Carlo simulations-provides consistent estimates in the presence of a fairly substantial share of zeros. However, to the best of our knowledge there is currently no STATA (or any other statistical package) command which allows for Tobit estimations with HD fixed effects. The STATA commands_reghdfe and ppml_panel_ $s g$ - enable faster computation of the many fixed effects required only for PPML and OLS structural gravity estimations, respectively.

${ }^{22}$ The IV sample reduces the numbers to 22 countries of destination (exporter) and 169 countries of origin (importer).
} 


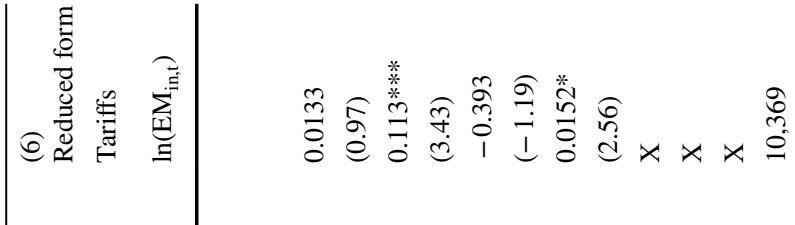

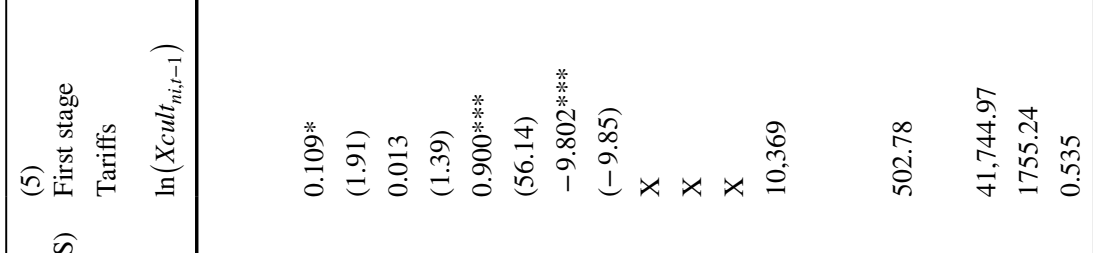

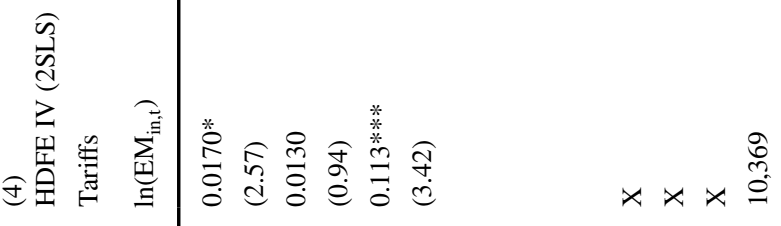

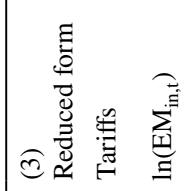

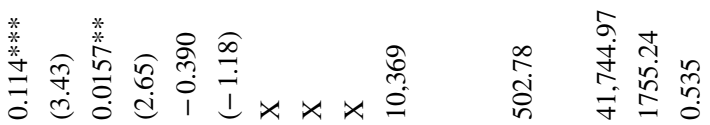

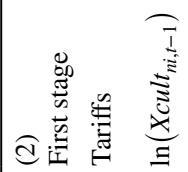

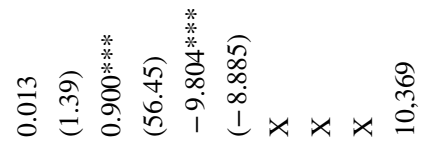

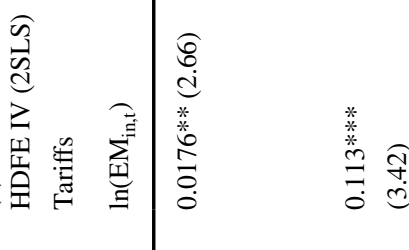

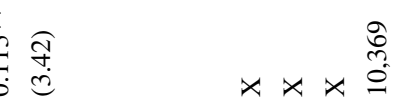

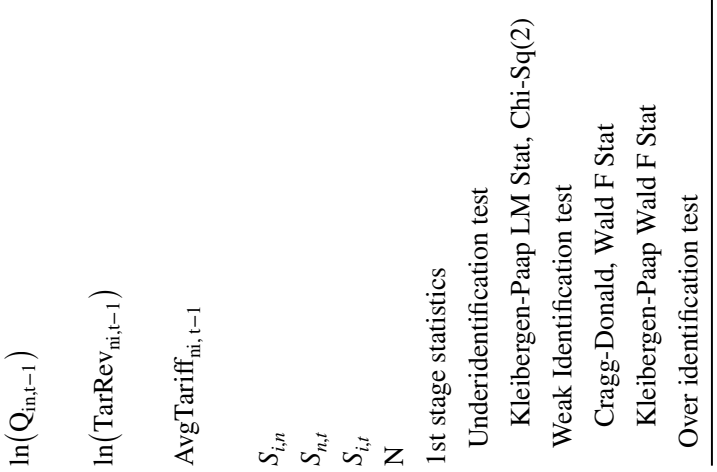




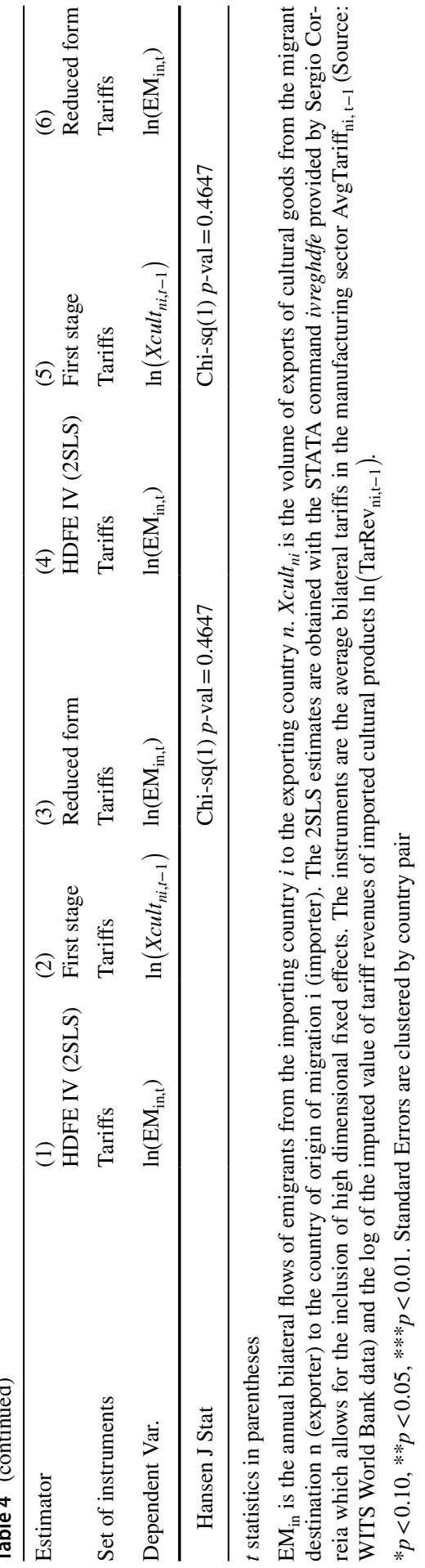


finding is in line with the baseline estimates reported in Column 5 of Table 2. All in all, the IV results essentially confirm the positive relationship that emerges from our baseline estimates and add consistency to our predictions on the importance role of cultural changes in the emigration decision. ${ }^{23}$

\subsection{Further addressing the measurement error bias}

Measurement error can bias the estimated impact of our parameters of interest. While the use of trade in cultural goods as proxy for CP has many advantages for the purpose of this analysis, there are potential concerns regarding its validity in reflecting national cultural contents.

For instance, American music labels might export records with non-American cultural content, so the imports of music from the US in some cases doesn't necessarily affect the perceived attractiveness towards the US culture. By the same token, French exports of fashion products (included in the UNCTAD classification of "optional" cultural goods) may not only reflect French cultural content, but also a third country's cultural content embedded in the fashion design that is performed before manufacturing takes place in France (see Fiorini et al. 2021). Further, custom data does not include digital transactions (i-tunes, Netflix) that accounted for a relevant share of transactions of several "core" cultural goods, such as DVDs, Music and Books. However, digital transactions have increased dramatically over the last 5-6 years, a period that falls outside our sample's time coverage, so the latter source of measurement error is unlikely to largely influence our results. ${ }^{24}$

To address the issues associated with measurement error in Table 5 we first compare the benchmark findings reported in Table 2 (Column 1) with the correspondent estimates obtained with the "core" UNESCO classification of cultural products (Column 4-5). The products identified by UNESCO as cultural goods are arguably characterized by a larger cultural content compared to the classification proposed by UNCTAD. They are therefore likely to better capture proximity in cultural tastes. However, as noted in "Appendix A3", UNESCO's classification implies the use of a more limited time span and is less representative of the cultural products traded by the South. Given the shorter time coverage we are not including our full set of

\footnotetext{
23 To further address reverse causality, we use the premium assigned by a trading partner to a country's non-cultural production as an instrument for cultural exports. We take inspiration from the strategy originally proposed by Frankel and Romer (1999) and construct the instrument based on deviations from a country's 'Natural Openness' to trade. Using deviations from a country's 'Natural Openness' to cultural trade as an instrument hinges on the idea that, assuming cultural preferences to be properly identified and the gravity model fitting adequately the data, every deviation between actual and structural flows reflects the cultural premium assigned to a country's cultural production by an economic partner (see Fiorini et al. 2021). Hence, subtracting the cultural premium from the deviations of total trade gives us a measure of the premium assigned to a country's non-cultural production. The validity of this IV hinges again on the evidence about the absence of statistically significant correlation between the time variation of non-cultural trade and emigration from importing countries. The results (available upon request) are very close our baseline findings, which we find reassuring.

24 Netflix more than doubled the number of Subscribers from 2013 till 2018, see https://www.theguardian.com/media/2017/apr/15/netflix-nudges-100m-subscribers-but-what-next-for-the-streaming-giantv
} 
FEs since the more limited information in the UNESCO sample would create problems in terms of identification power. Hence, we compare the two classifications only with country-year fixed effects. The results indicate that using a different classification does not alter our benchmark estimates and our main conclusions remain unchanged. Lastly, in Column (2-3) we propose trade in newspapers and other printed matter as a more refined/accurate alternative measure of cultural proximity (see "Appendix A3" for more details on these product categories). The idea behind this is that newspapers are less subject to the global value chain bias described above, as their production is not dislocated to foreign countries. This therefore minimizes the potential concerns regarding the measurement error introduced by the gross nature of cultural trade. The results point to a positive relationship between cultural changes and emigration, which corroborate our baseline estimates.

\subsection{Extensions}

This section proposes two extensions to the analysis conducted so far. We test whether the role of the time varying component of cultural proximity changes (a) at different levels of pre-existing cultural similarities and (b) when we account for the long-lasting effect of cultural goods in favoring cross-cultural convergence.

Table 6 explores the variation of the role of cultural proximity on emigration for different levels of pre-determined cultural affinity and stages of economic development.

We first divide our sample according to the degree of cross-country cultural affinity based on linguistic and genetic distance (Columns 1-4) as well as the average volume of cultural exports (Columns 5-6). In order to preserve enough identification power and to attenuate the selection bias we split the sample into, respectively, almost identical subgroups using the median of $f$ st_distance_dominant from Adsera and Pytlikova (2015), lp2 from Melitz and Toubal (2014) and the average value of cultural exports over our period of interest, respectively. ${ }^{25}$ Taken together, the results suggest that time contingent shocks to cultural proximity only play a role when historical cultural similarities between country pairs are relatively weak. This finding suggests a non-linear effect for cultural proximity on migration over pre-existing cultural ties and a potential role for trade in cultural products in promoting cultural convergence. ${ }^{26}$ In particular, the evidence is consistent with a relationship of

\footnotetext{
25 The choice of MaxPAll as a measure of linguistic proximity is due to the relatively larger number of observations available compared to other similar proxies included in Adsera Pytlikova (2015). Lp2 is considered to be better founded by Melitz and Toubal (2014) and a better basis for reasoning and their experiments among other similar proxies.

${ }^{26}$ The use of a squared term is often suggested in the literature to detect non-linearities. However, recent econometric studies show that the use of a squared term often leads to misleading results and false conclusions (e.g. Lind and Mehlum, 2010). While we rely on sampling split as the preferred strategy to detect non-linearities, we also included the quadratic term of VACP and found a non-linear (inverted-Ushape) relationship between cultural proximity and emigration rates The results are roughly in line with the findings presented in Table 6 i.e. while a positive relationship emerges for culturally distant countrypairs, the effect of VACP progressively dies away as countries become culturally closer. The estimates are available upon request.
} 
Table 5 Robustness check: UNCTAD versus UNESCO classification

\begin{tabular}{|c|c|c|c|c|c|}
\hline Estimator & $\begin{array}{l}(1) \\
\text { OLS }\end{array}$ & $\begin{array}{l}(2) \\
\text { OLS }\end{array}$ & $\begin{array}{l}(3) \\
\text { OLS }\end{array}$ & $\begin{array}{l}(4) \\
\text { OLS }\end{array}$ & $\begin{array}{l}(5) \\
\text { OLS }\end{array}$ \\
\hline \multirow[t]{4}{*}{ Classification } & UNCTAD & UNCTAD & UNCTAD & UNESCO & UNESCO \\
\hline & 2004-2013 & 2004-2013 & $2004-2013$ & $2008-2013$ & $2008-2013$ \\
\hline & Core + optional & Newspaper & Newspaper & Core & Core \\
\hline & $\ln \left(\mathrm{EM}_{\mathrm{in}, \mathrm{t}}\right)$ & $\ln \left(\mathrm{EM}_{\mathrm{in}, \mathrm{t}}\right)$ & $\ln \left(\mathrm{EM}_{\mathrm{in}, \mathrm{t}}\right)$ & $\ln \left(\mathrm{EM}_{\mathrm{in}, \mathrm{t}}\right)$ & $\ln \left(\mathrm{EM}_{\mathrm{in}, \mathrm{t}}\right)$ \\
\hline \multirow{2}{*}{$\ln \left(\right.$ Xcult $\left._{n i, t-1}\right)$} & $0.072 * * *$ & $0.029 * *$ & $0.009^{*}$ & $0.068 * * *$ & \\
\hline & $(6.56)$ & $(3.31)$ & (1.97) & (7.11) & \\
\hline \multirow[t]{2}{*}{$\ln \left(\alpha_{\mathrm{ni}, \mathrm{t}-1}\right)$} & & & & & $0.057 * * *$ \\
\hline & & & & & $(0.06)$ \\
\hline \multirow[t]{2}{*}{$\ln \left(X_{\mathrm{ni}, \mathrm{t}-1}\right)$} & & & & & $0.121 * * *$ \\
\hline & & & & & $(5.23)$ \\
\hline \multirow[t]{2}{*}{$\ln \left(\mathrm{Q}_{\mathrm{in}, \mathrm{t}-1}\right)$} & $0.553 * * *$ & $0.546^{* * * *}$ & $0.073^{*}$ & $0.574 * * *$ & $0.569 * * *$ \\
\hline & $(12.86)$ & $(11.28)$ & $(2.23)$ & $(13.20)$ & (12.97) \\
\hline \multirow[t]{2}{*}{$\ln \left(\right.$ dist $\left._{\text {in }}\right)$} & $-0.489 * * *$ & $-0.502 * * *$ & & $-0.456^{* * *}$ & $-0.382 * * *$ \\
\hline & $(-9.72)$ & $(-8.78)$ & & $(-8.90)$ & $(-7.66)$ \\
\hline \multirow[t]{2}{*}{ Colony $_{\text {in }}$} & $0.356 * *$ & $0.356 * *$ & & 0.217 & 0.165 \\
\hline & $(2.77)$ & $(2.77)$ & & $(1.86)$ & $(1.46)$ \\
\hline \multirow[t]{2}{*}{ Lang $_{\text {in }}$} & $0.399 * *$ & $0.386^{* *}$ & & $0.332 * * *$ & $0.368 * * *$ \\
\hline & $(4.64)$ & $(2.92)$ & & (4.09) & $(4 . .67)$ \\
\hline \multirow[t]{2}{*}{ Comleg $_{\text {in }}$} & 0.091 & $(0.092$ & & 0.090 & 0.078 \\
\hline & $(1.62)$ & $(1.62)$ & & $(1.77)$ & $(1.45)$ \\
\hline$S_{i, n}$ & & & $X$ & & \\
\hline$S_{n, t}$ & $X$ & $X$ & $X$ & X & $X$ \\
\hline$S_{i, t}$ & $X$ & $X$ & $X$ & $X$ & $X$ \\
\hline$N$ & 15,062 & 12,366 & 11,798 & 8315 & 8268 \\
\hline$R-s q$ & 0.90 & 0.90 & 0.98 & 0.90 & 0.90 \\
\hline
\end{tabular}

$t$ statistics in parentheses

$* p<0.10, * * p<0.05, * * * p<0.01$. Standard Errors are clustered by country pair. $\mathrm{EM}_{\mathrm{in}}$ is the annual bilateral flows of emigrants from the importing country $i$ to the exporting country $n$. Xcult $t_{n i}$ is the volume of exports of cultural goods from the migrant destination $n$ (exporter) to the country of origin of migration $\mathrm{i}$ (importer). The parameter of interest in column (2-3) is the effect of exports of newspapers and other printed matter on migration, while in columns (4-5) cultural goods are classified according to the core UNESCO classification

substitutability between the time-contingent, asymmetric and time-invariant, symmetric dimensions of cultural proximity in triggering migration, with the former operating as a bridgehead between otherwise culturally distant countries. A plausible explanation is that the cultural content embodied in these types of products enhances bilateral cultural affinity through what Tabellini (2008) defines as the horizontal transmission of values. The consumption and diffusion of cultural goods in countries of origin can contribute to transferring exporter's cultural traits, making the culture at destination better known, more attractive and more widely accepted. 
In Columns (7-8) we test whether positive shocks in $\mathrm{CP}$ influence migration between country-pairs at different stages of development. To do so, we split the sample according to what is typically classified as North-North vs South-North migration and define as North countries all the member states of the OECD included in our sample. Interestingly, the estimates suggest that the effect of the time-variation of cultural proximity comes from South-North migration. In other words, a positive shock of VACP — other factors held constant—raises emigration towards countries characterized by larger income differentials. While this finding corroborates the results reported in Columns (1-6) - as we expect that the cultural distance between OECD countries and non-OECD countries may be larger than between OECD countries-it also suggests that the role of cultural proximity in reducing moving costs appears to be particularly important in developing countries, where budgetary and credit constraints are more binding. Finally, when looking at the impact of diaspora across sub-samples, it appears to be stronger for North-North migration. This result is in line with the literature on the role of networks in micro-founded gravity models, as the elasticity of the stock of emigrants generally increases when focusing on emigration towards OECD destinations (see Beine et al. 2015). In addition, we do not consider this evidence at odds with our hypothesis-given that a larger diaspora coefficient might be explained by the skill composition of networks (Felbermayr \& Jung, 2009), for which we do not have data that fully cover our sample's time-span. ${ }^{27}$

While in this study we are employing cultural exports mainly as a proxy for "revealed cultural preferences", we are not ruling out the cultural transmission channel of cultural trade (Maystre et al. 2014), i.e. that cultural content embodied in cultural goods can transmit and diffuse information on values, beliefs, habits and cultural traits of migrant destinations in importing countries. This process would in turn lead to a rise in emigration from importing countries through a progressive cultural alignment between origin and destination countries. In Table 7 we explore more closely this potential long-lasting role of trade in cultural goods in favoring cross-country cultural convergence and its indirect impact on the decision to migrate. More specifically, we test whether the intensity of long-lasting bilateral cultural relationships have a stronger effect on migration. We are well aware that the transmission of values which shapes the utility of would-be migrants takes time (see Cavalli Sforza, 2001). ${ }^{28}$ For instance, the effect of traded movies on cross-country

\footnotetext{
27 To the best of our knowledge the only dataset that provides information on bilateral stocks of emigrants at different skill levels is Brücker et al. (2013). However, that dataset is restricted to a very limited number of OECD destinations and the data are available only for 5-year intervals. Hence, it would be of limited use for the purpose of our analysis.

28 Of course, cross-country cultural transmission of values takes place in a variety of ways, including the use of social networks and the internet. However, within the time coverage of our broad sample the use of the internet was rather limited and much less developed worldwide than one might think. Indeed, in 2005 , only $16 \%$ of the entire world population used the internet; the figure only increased to $40 \%$ by 2014 (Source: International Telecommunications Union). Digital transactions (i-tunes, Netflix)not accounted for in the classification of cultural goods - and the use of internet rapidly increased over the last 10 years. Hence, we believe it's "safer" to focus on the time span covered in our sample 20042013 - rather than relying on more recent data - as it lowers the risk of measurement error, i.e. variations in the demand of cultural goods from a given country of (migrant) destination better reflects variations on preferences/attractiveness for the culture of that country.
} 


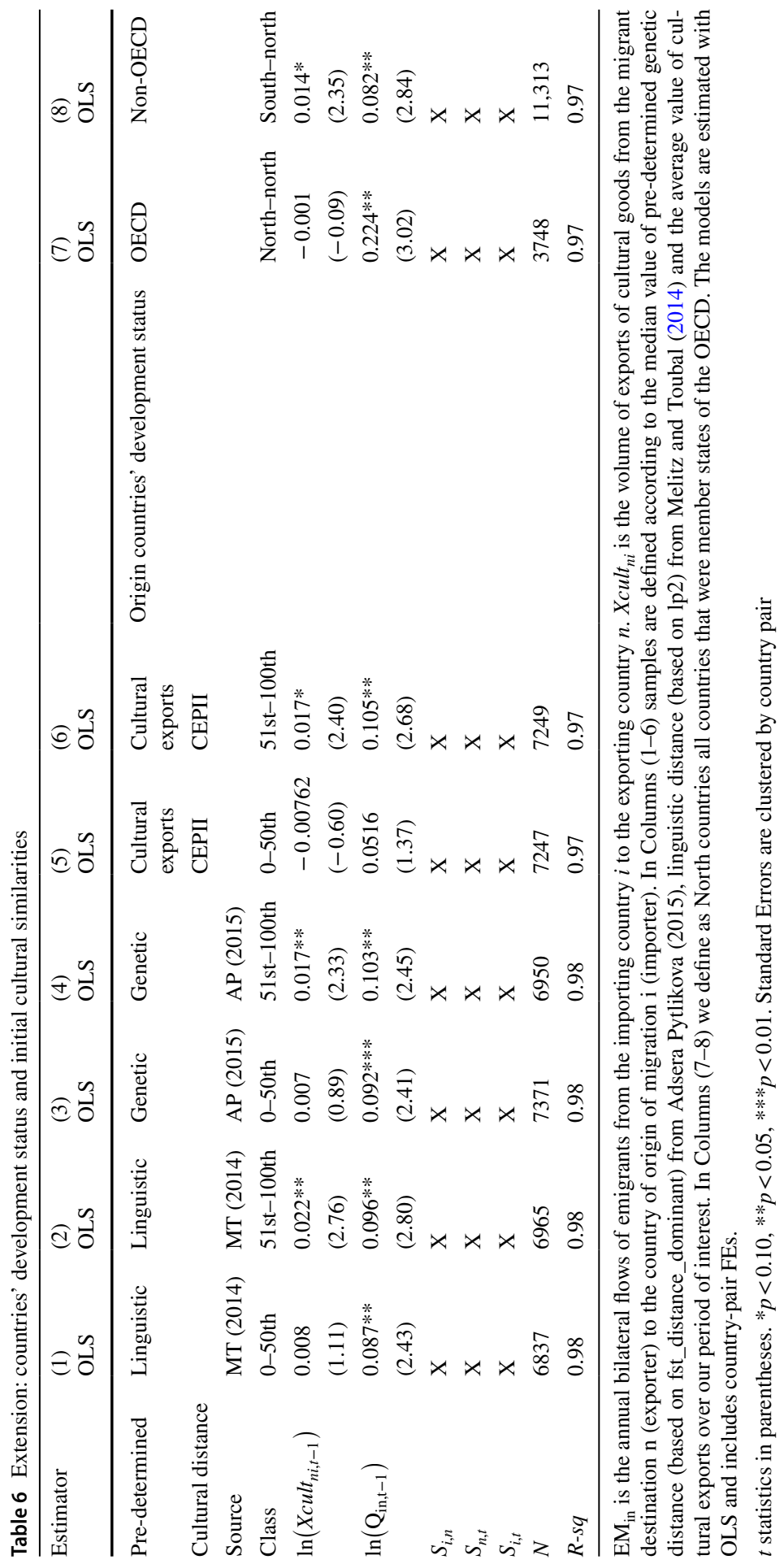


cultural pervasiveness is neither instantaneous or brief; rather, movies can be repeatedly watched and broadcast once purchased. Hence, our empirical strategy accounts for the recent history of bilateral trade relationships between $n$ and $i$ by simply considering the impact of the cumulative exports of cultural products from destination $n$, so that:

$$
\text { CumXcult }_{n i, t}=\sum_{t-1}^{t-s} \text { Xcult }_{n i, t}
$$

This strategy allows at the same time to attenuate the distortion due to business cycle factors and measurement error associated with trade data. We initially set $s=5$ while the third column reports the correspondent estimates with $s=9$. Interestingly, as $s$ goes up the impact of cultural exports tends to increase. In other words, when we add past bilateral cultural exported goods to Xcult ${ }_{n i, t-1}$ the impact of our variable of interest on the decision to migrate at time $t$ gets larger and larger. This finding is consistent with the hypothesis of a long-lasting effect of cultural products on bilateral cultural affinity.

Table 8 deals with the asymmetric dimension of time-contingent variations of cultural proximity in the context of international migration. To do so, we add imports of cultural goods to our gravity specification. We start with a parsimonious specification including only cultural imports in the model (Column 1), then progressively add other variables, namely imports of non-cultural goods (Column 2), exports of cultural (Column 3) and non-cultural goods (Column 4). Generally, the evidence indicates that the asymmetric component of VACP matters. Taken together, the results suggest that only the time-variation of cultural exports have a positive and significant effect on emigration from importing countries-i.e. the preference of the individuals in the importing country for the exporter's culture appears to be the only direction of cultural proximity that influences emigration decisions from importing countries. In other words - according to our conceptual framework-while a rise of, say, cultural affinity for Mexicans towards US culture leads to higher emigration to the US, the time variation of US preferences for Mexico's culture does not appear to affect Mexicans' emigration decisions. Finally, when restricting the analysis to the within variation of country-pairs both directions of trade in non-cultural products do not influence emigration flows.

\section{Conclusions}

Cultural barriers have been identified as one of the main drivers of international migration. They explain patterns of international migration which cannot be explained by merely looking at differences in terms of economic indicators. In other words, cultural factors help to address the so-called "immobility puzzle", which we can define-paraphrasing Trefler (1995)_as "the case of missing migration", i.e. very low migratory responses to large unemployment and wage differentials. In this context, proxies for cultural proximity such as linguistic and religious distance, along with more refined indicators, capturing (at least partially) the cultural 
orientation of countries, were found to have a positive impact on migration flows, after controlling for income differentials.

However, the common characteristics of these proxies - and, more generally, one of the implicit assumptions adopted in international migration gravity models-is that cultural proximity is time invariant and symmetric. These assumptions appear particularly strong and unrealistic when looking at the migratory patterns of the last two decades, given the growing exposure of citizens to foreign cultures through cross-border information flows, the globalization of mass communications and the rise of social media. All these channels may have affected the degree of cultural affinity of citizens towards potential destinations, without this affinity being necessarily reciprocated.

In this paper we relax these assumptions and propose a broader definition of cultural proximity which explicitly accounts for the asymmetric evolution of crosscultural relationships over time. In line with Disdier et al. (2010) and Fiorini et al. (2021), we use bilateral trade in cultural goods as a proxy for time-dependent and asymmetric cultural proximity. More precisely, we assume that the value of the bilateral exports of cultural goods reflects affinity towards the destination's (exporter's) culture for the citizens in the country of origin (importer). Our analysis contributes to the literature as the impact of the time-varying and asymmetric dimension of cultural proximity was too little studied in the context of international migration. The few existing studies on the impact of cultural barriers on migration choices were, meanwhile, predominantly focused on OECD countries as the point of origin of migrants, leaving out the whole spectrum of developing countries where the impact of cultural proximity on the decision to migrate might be particularly relevant.

Relying on a comprehensive set of high dimensional fixed effects and controlling for the size of diaspora, we find that the time variance of cultural proximity helps explaining international migration. More specifically, when accounting for pre-existing bilateral cultural ties, an increase of cultural affinity towards a potential destination enhances bilateral migration flows towards that destination. The results are robust across several robustness checks, including an IV strategy where exports of cultural goods are instrumented with tariff-related instrumental variables. Interestingly, when decomposing total exports between cultural and non-cultural flows, we find that the time variation of cultural exports seems to have a much more prominent role in explaining international migration patterns. This finding not only supports the validity of cultural exports as a proxy for VACP-whose impact on reverse emigration goes over and beyond the effect of aggregate trade flows-but also complements previous research on the trade-migration link (e.g. Campaniello, 2014) by distinguishing different types of trade flows. More specifically, when restricting the analysis to the within variation of country-pairs, trade in non-cultural products does not appear to influence emigration decisions from countries of origin. Furthermore, our findings suggest that the reverse channel of VACP — proxied by cultural imports-does not explain emigration flows. In other words, only the time variation of migrant preferences for destination's culture appears to affect emigration decisions. This result supports our theoretical considerations and corroborates the findings of Fiorini et al. (2021) and Felbermayr and Toubal (2010) on the asymmetric nature of cultural proximity. Finally, the positive impact of cultural proximity is 
Table 7 Extension: impact of 'Cumulative', cultural exports on the emigration rate

\begin{tabular}{|c|c|c|c|}
\hline Estimator & $\begin{array}{l}\text { (1) } \\
\text { OLS }\end{array}$ & $\begin{array}{l}\text { (2) } \\
\text { OLS }\end{array}$ & $\begin{array}{l}\text { (3) } \\
\text { OLS }\end{array}$ \\
\hline Dependent Var. & $\ln \left(\mathrm{EM}_{\mathrm{in}, \mathrm{t}}\right)$ & $\ln \left(\mathrm{EM}_{\mathrm{in}, \mathrm{t}}\right)$ & $\ln \left(\mathrm{EM}_{\mathrm{in}, \mathrm{t}}\right)$ \\
\hline $\ln \left(\sum_{t-1}^{t-s} X_{c u l t} t_{n i, t-1}\right)$ & $\begin{array}{l}0.073 * * * \\
(5.11)\end{array}$ & $\begin{array}{l}0.028 * \\
(2.45)\end{array}$ & $\begin{array}{l}0.038 * * \\
(2.40)\end{array}$ \\
\hline $\ln \left(X_{\mathrm{in}, \mathrm{t}-1}\right)$ & $\begin{array}{l}0.044 * * * \\
(4.15)\end{array}$ & $\begin{array}{l}-0.000 \\
(-0.13)\end{array}$ & $\begin{array}{l}-0.000 \\
(-0.16)\end{array}$ \\
\hline $\ln \left(Q_{\mathrm{in}, \mathrm{t}-1}\right)$ & $\begin{array}{l}0.544 * * * \\
(12.47)\end{array}$ & $\begin{array}{l}0.093^{* *} \\
(3.24)\end{array}$ & $\begin{array}{l}0.093 * * * \\
(3.22)\end{array}$ \\
\hline $\ln \left(\right.$ dist $\left._{\text {in }}\right)$ & $\begin{array}{l}-0.450 * * * \\
(-9.02)\end{array}$ & & \\
\hline Colony $_{\text {in }}$ & $\begin{array}{l}0.340 * * * \\
(2.70)\end{array}$ & & \\
\hline Lang $_{\text {in }}$ & $\begin{array}{l}0.409 * * \\
(4.82)\end{array}$ & & \\
\hline Comleg $_{\text {in }}$ & $\begin{array}{l}0.065 \\
(1.11)\end{array}$ & & \\
\hline Cumulative exports & $s=5$ & $s=5$ & $s=9$ \\
\hline$S_{i, n}$ & & $X$ & $\mathrm{X}$ \\
\hline$S_{n, t}$ & $\mathrm{X}$ & $X$ & $X$ \\
\hline$S_{i, t}$ & $X$ & X & X \\
\hline$N$ & 14,909 & 14,909 & 14,909 \\
\hline$R-s q$ & 0.90 & 0.98 & 0.98 \\
\hline
\end{tabular}

$t$ statistics in parentheses

$\mathrm{EM}_{\mathrm{in}}$ is the annual bilateral flows of emigrants from the importing country $i$ to the exporting country $n$. Xcult $t_{n i}$ is the volume of exports of cultural goods from the migrant destination $n$ (exporter) to the country of origin of migration i (importer). The first column includes country*year Fes; the second and the third columns the model includes also country pair FEs and all the covariates that are time invariant are automatically dropped. The estimates are obtained with the STATA command reghdfe provided by Sergio Correia which allows for the inclusion of high dimensional fixed effects. Exports are calculated as the cumulative bilateral inflows in the 5 years period between $t-5$ and $t-1$. Trade flows are transformed from Current to 2010 Constant US Dollars using US 2010 Consumer Price Index. In the third column, exports are cumulated from $t-9$ and $t-1$. The dependent variable in the OLS specification is the $\log$ of the bilateral emigration rate. Cultural products are defined according to the HSO2 classification of creative goods provided by UNCTAD.

${ }^{*} p<0.10, * * p<0.05, * * * p<0.01$. Standard Errors are clustered by country pair

found to be even stronger for culturally diverse country pairs, and when the longlasting effect of cultural goods in favoring cross-cultural convergence is taken into account. The latter finding sheds some light on the positive role of trade integration 
Table 8 Extension: asymmetric cultural proximity

\begin{tabular}{|c|c|c|c|c|}
\hline Estimator & (1) OLS & (2) OLS & (3) OLS & (4) OLS \\
\hline Dependent Var & $\ln \left(\mathrm{EM}_{\mathrm{in}, \mathrm{t}}\right)$ & $\ln \left(\mathrm{EM}_{\mathrm{in}, \mathrm{t}}\right)$ & $\ln \left(\mathrm{EM}_{\mathrm{in}, \mathrm{t}}\right)$ & $\ln \left(\mathrm{EM}_{\mathrm{in}, \mathrm{t}}\right)$ \\
\hline \multirow[t]{2}{*}{$\ln \left(X_{c u l t} t_{i n, t-1}\right)$} & 0.00876 & 0.00867 & 0.0101 & 0.0101 \\
\hline & $(1.32)$ & (1.29) & $(1.54)$ & $(1.54)$ \\
\hline \multirow{2}{*}{$\ln \left(\right.$ XNoncult $\left._{\text {in,t-1 }}\right)$} & & 0.00772 & -0.000965 & -0.000965 \\
\hline & & $(0.98)$ & $(-0.12)$ & $(-0.12)$ \\
\hline \multirow[t]{2}{*}{$\ln \left(X_{c u l t} t_{n i, t-1}\right)$} & & & $0.0151 * *$ & $0.0151 * *$ \\
\hline & & & $(2.42)$ & $(2.42)$ \\
\hline \multirow[t]{2}{*}{$\ln \left(\right.$ XNoncult $\left._{n i, t-1}\right)$} & & & 0.0181 & 0.0181 \\
\hline & & & $(1.25)$ & $(1.25)$ \\
\hline \multirow[t]{2}{*}{$\ln \left(Q_{\mathrm{in}, \mathrm{t}-1}\right)$} & $0.101 * * *$ & $0.101 * * *$ & $0.0969 * * *$ & $0.0969 * * *$ \\
\hline & $(3.11)$ & (3.09) & $(2.97)$ & $(2.97)$ \\
\hline$S_{i, n}$ & $X$ & $\mathrm{X}$ & $X$ & $\mathrm{X}$ \\
\hline$S_{n, t}$ & $\mathrm{X}$ & $\mathrm{X}$ & $\mathrm{X}$ & $\mathrm{X}$ \\
\hline$S_{n, t}$ & $\mathrm{X}$ & $\mathrm{X}$ & $\mathrm{X}$ & $\mathrm{X}$ \\
\hline Ns & 13,636 & 13,590 & 12,907 & 12,907 \\
\hline$R-s q$ & 0.97 & 0.98 & 0.98 & 0.98 \\
\hline
\end{tabular}

$t$ statistics in parentheses

$\mathrm{EM}_{\mathrm{in}}$ is the annual bilateral flows of emigrants from the importing country $i$ to the exporting country $n$. $X_{\text {cult }}$ ii is the volume of exports of cultural goods from the migrant destination $\mathrm{n}$ (exporter) to the country of origin of migration i (importer). Xcult in is the volume of imports of cultural goods from the migrant origin $\mathrm{i}$ (importer) to the migrant destination (exporter)

${ }^{*} p<0.10,{ }^{* *} p<0.05,{ }^{* * *} p<0.01$. Standard Errors are clustered by country pair

in cultural goods in favoring migration through a progressive cultural alignment between origin and destination countries.

This paper leaves interesting avenues for policy analyses and future research. First, more disaggregated analyses would constitute an important step towards arriving at more nuanced policy conclusions. For instance, exploring how the effect of cultural shocks on migration decisions vary with the level of importing countries' cultural heterogeneity would help providing a more detailed picture of the link between cultural proximity and migration decisions. This of course implies relaxing the assumption of within-country cultural homogeneity. Further, empirical research is also needed to better understand how positive variations of cultural proximity influence emigration at different skill levels. One would expect a larger impact on the highly skilled, those who are more used to diversity and plausibly more open to external values. Second, our findings suggest a stronger positive impact from exports of cultural goods when historical cultural similarities between country pairs are relatively weak. The evidence is consistent with a relationship of substitutability between time-contingent and time-invariant dimensions of cultural proximity in triggering migration, with the former operating as a bridgehead between otherwise culturally distant countries. Further research should be conducted to understand the role of the trade in cultural goods in shaping cultural values and triggering cultural convergence. Lastly, policies and programmes aimed at promoting national cultures 
in foreign countries (e.g. Korea) may have unintended consequences on the expected costs associated with migrant integration. By lowering the psychological and moving costs associated with adjusting to a new cultural environment, these policies can potentially reduce future integration costs in destination countries as emigrants adapt more easily to the values and habits of the hosting communities (Berry, 1980).

\title{
Appendix: Cultural change and the migration choice
}

\author{
See Box 1 and Fig. 3.
}

Box 1 The Korean wave "Hallyu"

\begin{abstract}
The case of the so-called Korean Wave (Hallyu) illustrates how positive shocks of CP, which do not depend on pre-existing cultural ties, proxied by cultural exports can lead to more intense bilateral economic exchanges and larger migration flows. Despite the absence of either a common cultural; religious; or linguistic background, the 2000s experienced an unprecedented penetration (and appreciation) of Korean soap operas and pop music (K-pop) in foreign countries. This occured especially in South East Asia over the period 1999-2010 and more recently in South America. Observers have started to identify a connection between the Korean Wave's success and more intense economic relationships. For instance, Chang and Lee (2018) found that exports of Korean TV shows are strongly correlated with an increase in Korean exports of clothes and cosmetics, targeting consumers more exposed to Korean cultural content. According to our hypothesis, the same mechanisms apply to international migration: the popularity (and greater appreciation) of the Korean culture in the importing country is likely to affect the selection process of emigrant destinations, resulting in larger emigration flows to Korea. Castles et al. (2015) employ the popularity of Korean culture as an alternative indicator of cultural distance using the number of views by each country of K-pop singer "Psy's Gentleman's" music video on YouTube. They postulate that the shorter the cultural distance, the more popular the Korean wave is in the country of origin, and the greater the possibility of international migration to Korea. They found evidence of a positive association between the popularity of the Korean culture in the sending country and emigration to Korea. We cannot include Korea in our sample, as we don't have information on the bilateral stocks of emigrants living in Korea from the same source (OECD). However, we can still provide some evidence on the correlation between the variation of Korean cultural exports and the evolution of reverse bilateral emigration flows to Korea over time. Figure B1 illustrates this case study for selected South-East Asian countries that are both geographically as well as culturally distant from Korea, namely The Philippines and Malaysia. These Asian countries of origin were selected following the breakthrough and extreme popularity of the Korean Wave in Asia until 2010, which roughly coincide with our period of interest. The trends over time show that an increase in cultural exports to those countries is associated with a rise in reverse emigration flows. Of course, the positive relationship that emerges from these trends might be due to time and country specific factors that are not controlled for. To this matter, we regress dyadic emigration flows to Korea from all sending countries on bilateral cultural exports by including origin and year fixed effects. The model is estimated with OLS and the coefficients are reported in Table 10. The results support our hypothesis on the effect of the Korean wave on the selection process in the choice of migration destinations: the more popular the Korean wave is in the sending countries through larger volumes of cultural exports, the more emigrants choose South Korea as their preferred destination.
\end{abstract}



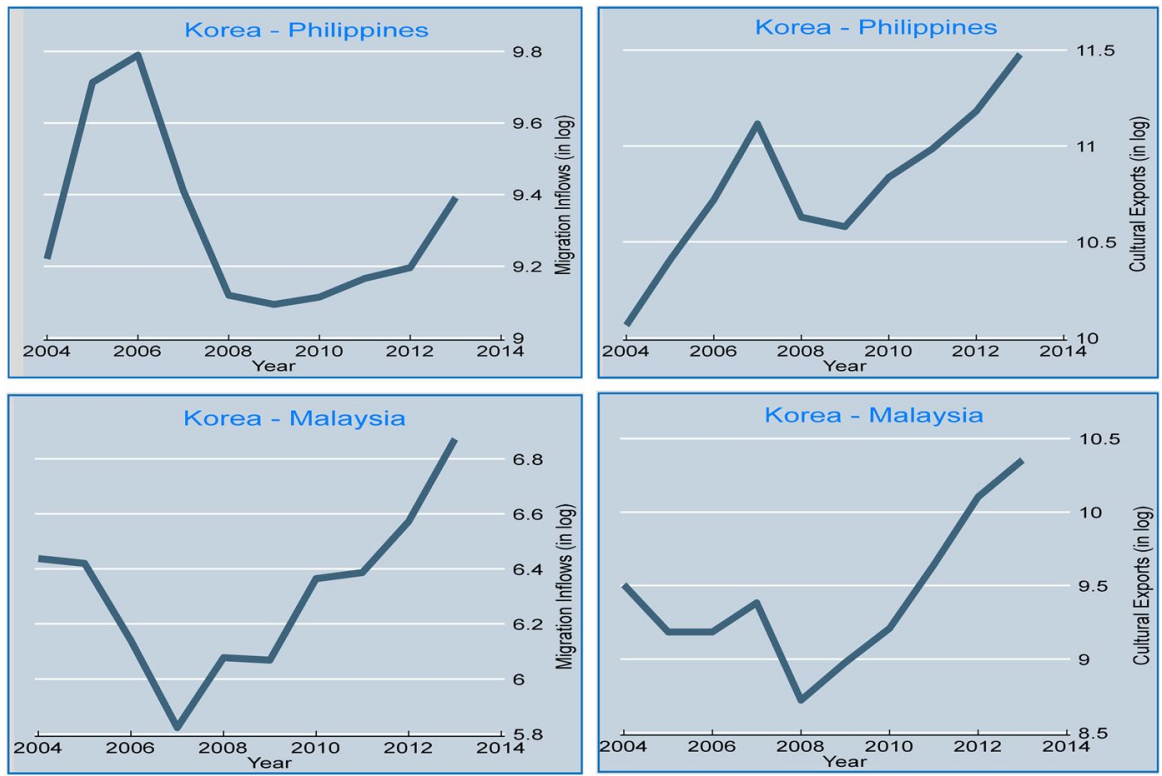

Fig. 3 Korean cultural exports to selected Asian countries and immigration flows. Notes Correlation between Korean cultural exports to Philippines (top panel) and Malaysia (bottom panel) and the evolution of reverse bilateral emigration flows to Korea over time

Table 10 Korean cultural exports and immigration flows

\begin{tabular}{lll}
\hline Estimator & $(1)$ OLS & $(2)$ OLS \\
\hline Dependent Var & $\ln \left(\mathrm{EM}_{\mathrm{in}, \mathrm{t}}\right)$ & $\ln \left(\mathrm{EM}_{\mathrm{in}, \mathrm{t}}\right)$ \\
$\ln \left(\right.$ Xcult $\left._{\text {in,t }}\right)$ & $0.0657^{* * *}$ & \\
& $(3.35)$ & \\
$\ln \left(X_{\text {ni,t }}\right)$ & & $0.166^{* * * *}$ \\
& & $(4.97)$ \\
$\ln \left(\right.$ Share $\left._{n i, t}\right)$ & & $0.0436^{*}$ \\
& & $(2.16)$ \\
$N$ & 1673 & 1673 \\
$S n$ & $\mathrm{X}$ & $\mathrm{X}$ \\
$S t$ & $\mathrm{X}$ & $\mathrm{X}$ \\
\hline
\end{tabular}

$t$ statistics in parentheses. Robust Standard Errors are included $* p<0.05$, ** $p<0.01$, *** $p<0.001$. The table shows the effect of Korean cultural exports from reverse migration from importing countries. The share of cultural exports is defined as in Table 2 


\section{A1 Link between cultural trade and time invariant proxies for cultural proximity}

In this Section, similarly to Felbermayr and Toubal (2010) and Guiso et al. (2009), we show that imports of cultural goods reflect time-invariant components of cultural similarities. We also argue that their time and within country-pair variance are strongly associated to the broad definition of cultural proximity proposed by sociologists (see Felbermayr \& Toubal, 2010).

Table 11 shows pairwise correlation coefficients between Imports of Cultural goods and standard pre-determined measures of cultural similarities. Among these measures we include the log of weighted distance, a dummy for a common colonial past (CEPII) and measures of linguistic and genetic distance from Adserà and Pytlikovà (2015). In addition we compute correlations with measures of the size of networks (OECD) along with the religious distance and the composite Hofstede Index from Belot and Ederveen (2012). In particular, this composite Index has been one of the main workhorses for the empirical test of the impact of cultural affinity on economic exchanges such as trade and FDI (see for instance Fiorini et al. 2021), but other than being at the same time pre-determined and symmetric, has the drawback of covering a fairly limited sample. The correlation coefficient between both cultural imports measures and the conventional proxies of cultural and geographical proximity all have the right sign and are statistically different from zero.

Table 12 reports the results of a simple regression which closely resembles to the gravity models proposed by Disdier et al. (2010) where trade in cultural goods is explained by time invariant measures of cultural similarities. Compared to Table 12 we also include imports of non-cultural goods among the explanatory variables. Interestingly, while all measures are strongly related to cultural imports in pairwise correlations, the regression analysis shows that religious and genetic distance as well

Table 11 Correlation coefficients between different measures of static cultural proximity

\begin{tabular}{lc}
\hline & $\ln \left(\right.$ ImpCultLevel $\left._{\text {ni,t }}\right)$ \\
\hline lnGeoDist $_{\text {in }}$ & $\mathbf{- 0 . 4 9 9 * * *}$ \\
LangProx $_{\mathrm{ni}}$ & $\mathbf{0 . 3 5 7 * * *}$ \\
ReligionDist $_{i n}$ & $\mathbf{- 0 . 1 9 5 * * *}$ \\
$\ln \left(\right.$ ImmStock $\left._{i n, \mathrm{t}}\right)$ & $\mathbf{0 . 7 2 4} * * *$ \\
Hofstede $_{\text {in }}$ & $\mathbf{- 0 . 2 4 5 * * *}$ \\
GeneticDist $_{\text {in }}$ & $\mathbf{- 0 . 1 4 8 * * *}$ \\
Colony $_{\mathrm{ni}}$ & $\mathbf{0 . 1 6 5 * * *}$ \\
\hline
\end{tabular}

Number of observations: 2210

The pairwise correlations are between imports of cultural goods and geographical, linguistic and genetic distance, a dummy for common colonial past (CEPII). Among the proxies for cultural proximity we also included religious distance and the Hofstede Index from Belot and Ederveen (2012). Given the relatively small country coverage of the Religious Distance and the Hofstede Index database the sample is limited to 19 OECD countries

***Denotes that coefficient is different from zero at $1 \%$ level of significance 
Table 12 Explaining trade in cultural goods

\begin{tabular}{|c|c|}
\hline Estimator & OLS \\
\hline Dep. Variable & $\ln \left(\right.$ ImpCultLevel $\left._{\mathrm{ni}, \mathrm{t}}\right)$ \\
\hline ImpNoCult $_{\mathrm{in}, \mathrm{t}-1}$ & $\begin{array}{l}\mathbf{0 . 5 8 4}^{* * *} \\
(6.84)\end{array}$ \\
\hline lnGeoDist $_{\text {in }}$ & $\begin{array}{l}-\mathbf{0 . 6 5 9} \\
(-6.80)\end{array}$ \\
\hline LangProx $_{\text {in }}$ & $\begin{array}{l}\mathbf{0 . 5 5 6} 6^{* * * *} \\
(2.73)\end{array}$ \\
\hline ReligionDist $_{\text {in }}$ & $\begin{array}{l}-0.036 \\
(-0.20)\end{array}$ \\
\hline $\ln (\operatorname{ImmStock} \mathrm{in}, \mathrm{t})$ & $\begin{array}{l}0.051 \\
(1.23)\end{array}$ \\
\hline Hofstede $_{\text {in }}$ & $\begin{array}{l}-\mathbf{0 . 7 3 3} \\
(-3.20)\end{array}$ \\
\hline GeneticDist $_{\text {in }}$ & $\begin{array}{l}-0.001 \\
(-0.67)\end{array}$ \\
\hline Colony $_{\text {in }}$ & $\begin{array}{l}\mathbf{0 . 3 4 2} \\
(1.82)\end{array}$ \\
\hline$S_{n, t}$ & $\mathrm{X}$ \\
\hline$S_{i, t}$ & $\mathrm{X}$ \\
\hline$N$ & 2210 \\
\hline$R-s q$ & 0.93 \\
\hline
\end{tabular}

$t$ statistics in parentheses; $* p<0.05$; Standard Errors are clustered by country pair. The model includes the intercept and importeryear, as well as exporter-year fixed effects. The dependent variable is bilateral aggregate imports of cultural goods (BACI,CEPII) which is regressed on geographical, linguistic and genetic distance, and a dummy for common colonial past (CEPII). Among the covariates we included religious distance and the Hofstede Index from Belot and Ederveen (2012). Given the relatively small country coverage of the Religious Distance and the Hofstede Index database the sample is limited to 19 OECD countries

as the size of the network does not matter for trade in cultural products. This might be due to the large impact of the Hofstede Index which plausibly captures much of the impact of other measures of cultural similarities. The results clearly indicate that Imports of cultural goods greatly depend on pre-determined components of cultural similarities.

\section{A2 definition and sources}

See Table 13. 


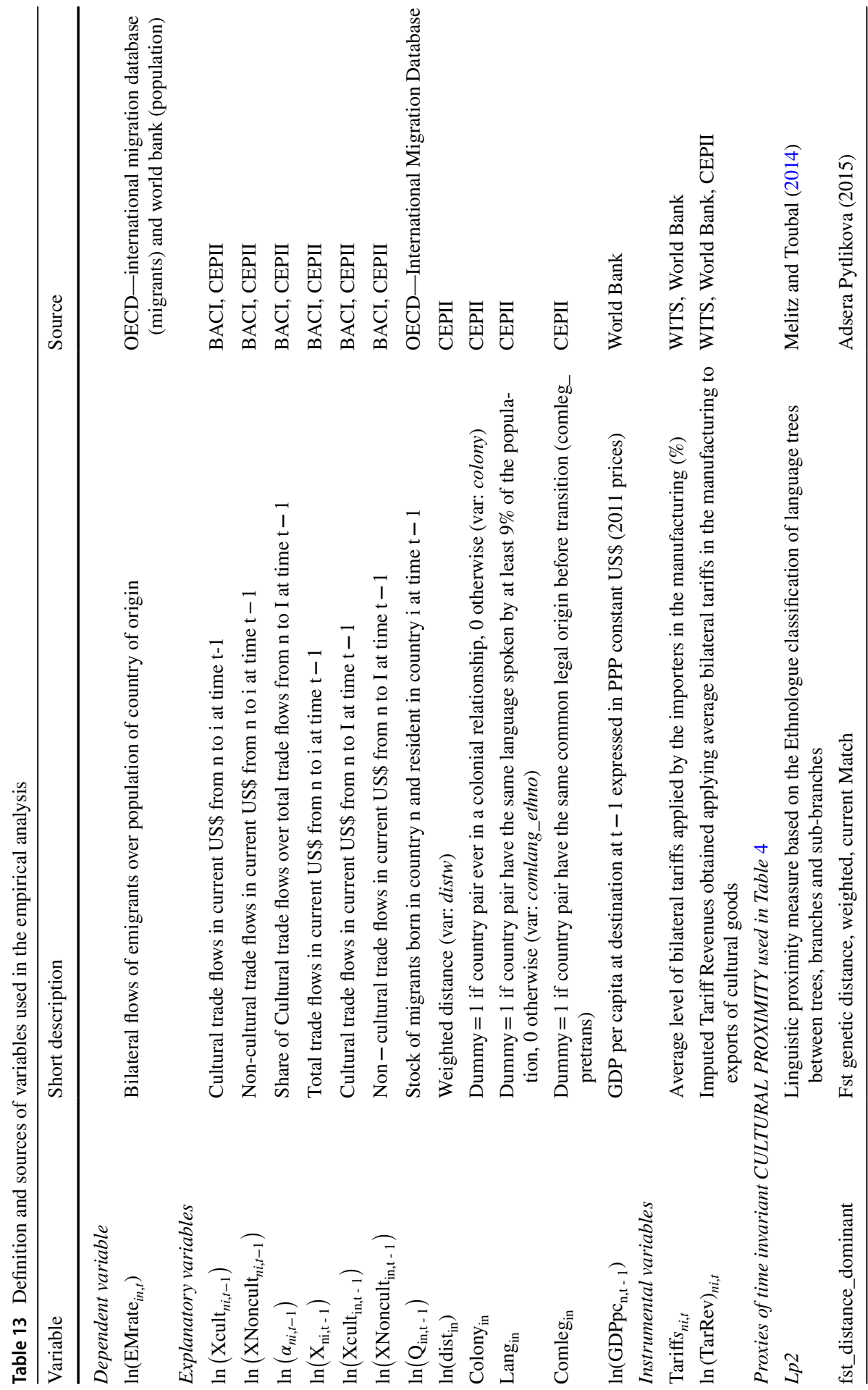




\section{A3 UNCTAD versus UNESCO classifications}

A crucial issue for our analysis concerns the definition of what products can be considered as "cultural goods". Two alternative classifications for cultural goods have been proposed by two different United Nations Organizations (UNESCO and UNCTAD), each of them based on slightly different criteria and different categories of goods to be included. As opposed to Disdier et al. (2010)—who classified cultural/creative goods according to the definition promoted by UNESCO-we rather adopt the scheme proposed by UNCTAD (2010). Our choice hinges on two main reasons: the first one-more substantial-concerns the countries' selection; the second-more technical-is related to the different coding system adopted by the two classifications.

- Although the two frameworks apply different versions of HS codes, UNESCO and UNCTAD embrace some common underlying principles for capturing the exclusive creative/cultural goods. However, according to the data from UN COMTRADE database, the 'core"' categories provided by UNESCO are dominated by developed economies, whereas the "optional" domains more represented in the broader UNCTAD classification stand for the predominant share of cultural imports in the developing countries. ${ }^{29}$ Since our analysis includes a very large number of developing and transition economies as countries of origin, we argue that UNCTAD classification is more adequate as it balances the cultural composition of trade flows by guaranteeing a relatively more comparable measure of cultural trade across countries at different development stages.

- The most recent and updated classification adopted by UNESCO is the 2007's Harmonized Commodity Description and Coding System (HS 2007). The use of HS07 would imply a more limited time span as the first available year would be 2008, which would call for the adoption of conversion tables in order to extend the time coverage. One of the drawbacks of using conversion tables is that different levels of disaggregation across HS classifications may create distortions in the definition of "cultural products". Conversely, UNCTAD (2010) adopts the HS02 coding system, which naturally allows for larger time series information. For the purpose of this paper the larger sample size is particularly important in terms of identification power given the important number of high dimensional fixed effects included in the specification, hence UNCTAD is preferred. In one of the extensions in Sect. 4.3 the cumulative exports are aggregated over 9 years, therefore conversion tables (HS92 to HS02) have been utilized.

Combining these two observations, the selection of cultural classification implies a trade-off between the cultural content embodied in these goods and the representation

\footnotetext{
${ }^{29}$ For instance, the UNCTAD classification encompasses more product groups-namely carpets, paperware, fashion, interior and toys - and therefore more product codes (209). In comparison, the UNCTAD classification emphasizes more-and puts more weight on-Design and Art Crafts categories, which encompass some three quarters of total creative product codes. We remind for a more detailed discussion to the reports UNCTAD (2010) and UNESCO (2013).
} 
Table 14 Classifications of cultural products

Code Label

UNCTAD classification of creative goods

CEROO1

CERO02

CEROO9

570110

570190

570210

570220

570231

570232

570239

570241

570242

570249

570251

570292

All creatives goods

Art crafts

Carpets

Carpets and other textile floor coverings, of wool or fine animal hair, knotted, whether or not made-up

Carpets and other textile floor coverings, of textile materials, knotted, whether or not made-up (excl. those of wool or fine animal hair)

Kelem, Schumacks, Karamanie and similar handwoven rugs, whether or not made-up

Floor coverings of coconut fibres "coir", woven, whether or not made-up

Carpets and other floor coverings, of wool or fine animal hair, woven, not tufted or flocked, of pile construction, not made-up (excl. Kelem, Schumacks, Karamanie and similar handwoven rugs)

Carpets and other floor coverings, of man-made textile materials, woven, not tufted or flocked, of pile construction (excl. Kelem, Schumacks, Karamanie and similar handwoven rugs)

Carpets and other floor coverings, of vegetable textile materials or coarse animal hair, woven, not tufted or flocked, of pile construction, not made-up (excl.

Kelem, Schumacks, Karamanie and similar handwoven rugs, and floor coverings of coconut fibre...

Carpets and other floor coverings, of wool or fine animal hair, woven, not tufted or flocked, of pile construction, made-up (excl. Kelem, Schumacks, Karamanie and similar handwoven rugs, plus Axminster and Wilton carpets)

Carpets and other floor coverings, of man-made textile materials, woven, not tufted or flocked, of pile construction, made-up (excl. Kelem, Schumacks, Karamanie and similar handwoven rugs)

Carpets and other floor coverings, of vegetable textile materials or coarse animal hair, woven, not tufted or flocked, of pile construction, not made-up (excl. Kelem, Schumacks, Karamanie and similar handwoven rugs, and floor coverings of coconut fibre...

Carpets and other floor coverings, of wool or fine animal hair, woven, not tufted or flocked, not of pile construction, not made-up (excl. Kelem, Schumacks, Karamanie and similar handwoven rugs)

Carpets and other floor coverings, of man-made textile materials, woven, not tufted or flocked, not of pile construction, not made-up (excl. Kelem, Schumacks, Karamanie and similar handwoven rugs)

Carpets and other floor coverings, of vegetable textile materials or coarse animal hair, woven, not tufted or flocked, not of pile construction, not made-up (excl. Kelem, Schumacks, Karamanie and similar handwoven rugs, and floor coverings of coconut $\mathrm{f}$...

Carpets and other floor coverings, of wool or fine animal hair, woven, not tufted or flocked, not of pile construction, made-up (excl. Kelem, Schumacks, Karamanie and similar handwoven rugs)

Carpets and other floor coverings, of man-made textile materials, woven, not tufted or flocked, not of pile construction, made-up (excl. Kelem, Schumacks, Karamanie and similar handwoven rugs) 
Table 14 (continued)

\begin{tabular}{ll}
\hline Code & Label \\
\hline 570299 & $\begin{array}{l}\text { Carpets and other floor coverings, of vegetable textile materials or coarse animal } \\
\text { hair, woven, not tufted or flocked, not of pile construction, made-up (excl. } \\
\text { Kelem, Schumacks, Karamanie and similar handwoven rugs, and floor coverings } \\
\text { of coconut fibre... }\end{array}$ \\
& $\begin{array}{l}\text { Carpets and other floor coverings, of man-made textile materials, tufted "needle } \\
\text { punched", whether or not made-up (excl. those of nylon or other polyamides) }\end{array}$ \\
570330 & $\begin{array}{l}\text { Celebration } \\
\text { CER010 }\end{array}$ \\
950510 & and Christmas articles (excl. candles and electric lighting sets, natural Christmas trees \\
950590 & Festival, carnival or other entertainment articles, incl. conjuring tricks and novelty \\
950810 & jokes, n.e.s \\
CER011 & Travelling circuses and travelling menageries \\
& Other
\end{tabular}

Wood marquetry and inlaid wood; caskets and cases for jewellery or cutlery, and similar articles, of wood; wooden articles of furniture (excl. statuettes and other ornaments; furniture, lighting fixtures and parts thereof)

Artificial flowers, foliage and fruit and parts thereof, and articles made of artificial flowers, foliage or fruit, by binding, glueing, fitting into one another or similar methods (excl. of plastics)

Glass eyes (excl. prosthetic articles); articles of glass beads, or of imitation pearls, imitation precious or semi-precious stones, statuettes and other ornaments of lamp-worked glass (excl. imitation jewellery)

Worked ivory and articles of ivory, n.e.s

Worked bone, tortoise-shell, horn, antlers, coral, mother-of-pearl and other animal carving material, and articles of these materials, n.e.s. (excl. ivory)

Worked vegetable or mineral carving material and articles of these materials n.e.s; moulded or carved articles of wax, of paraffin, of stearin, of natural gums or natural resins or of modelling pastes, and other moulded or carved articles n.e.s; worked...

\section{Paperware}

Handmade paper and paperboard of any size or shape

Wickerware

Mats, matting and screens of vegetable plaiting materials, flat-woven or bound together in parallel

Plaits and similar products of plaiting materials, whether or not assembled into strips; plaiting materials, plaits and similar products of vegetable plaiting materials, flat-woven or bound together in parallel (excl. mats, matting and screens; wall co...

Plaiting materials, plaits and similar products of non-vegetable plaiting materials, flat-woven or bound together in parallel (excl. wall coverings of heading 4814; parts of footware or headgear)

Basketwork, wickerwork and other articles, made directly to shape from plaiting materials or made-up from goods of heading 4601, and articles of loofah (excl. wall coverings of heading 4814; twine, cord and rope; footware and headgear and parts thereof...

Hand-made lace in the piece, in strips or in motifs (excl. fabrics of heading 6002 to 6006$)$ 
Table 14 (continued)

\begin{tabular}{|c|c|}
\hline Code & Label \\
\hline 580500 & $\begin{array}{l}\text { Hand-woven tapestries of the type Gobelin, Flanders, Aubusson, Beauvais and } \\
\text { the like, and needle-worked tapestries, e.g. petit point, cross-stitch, whether or } \\
\text { not made-up (excl. Kelem, Schumacks, Karamanie and the like, and tapes- } \\
\text { tries }>100 \text { years old) }\end{array}$ \\
\hline 580610 & $\begin{array}{l}\text { Narrow woven pile fabrics, incl. terry towelling and similar terry fabrics, and } \\
\text { chenille fabrics (excl. labels, badges and similar articles) }\end{array}$ \\
\hline 580620 & $\begin{array}{l}\text { Narrow woven fabrics of textile materials, containing }>=5 \% \text { elastomeric yarn } \\
\text { or rubber thread by weight (excl. woven pile fabrics, incl. terry towelling and } \\
\text { similar terry fabrics, chenille fabrics, and labels, badges and similar articles) }\end{array}$ \\
\hline 580631 & Narrow woven fabrics of cotton, n.e.s \\
\hline 580632 & Narrow woven fabrics of man-made fibres, n.e.s \\
\hline 580639 & $\begin{array}{l}\text { Narrow woven fabrics of textile materials other than cotton or man-made fibres, } \\
\text { n.e.s }\end{array}$ \\
\hline 580640 & $\begin{array}{l}\text { Narrow fabrics consisting of warp without weft assembled by means of an adhe- } \\
\text { sive "bolducs" }\end{array}$ \\
\hline 580810 & Braids in the piece \\
\hline 580890 & $\begin{array}{l}\text { Ornamental trimmings of textile materials, in the piece, not embroidered, other } \\
\text { than knitted or crocheted; tassels, pompons and similar articles of textile materi- } \\
\text { als (excl. braids in the piece) }\end{array}$ \\
\hline 580900 & $\begin{array}{l}\text { Woven fabrics of metal thread and woven fabrics of metallized yarn of heading } \\
5605 \text {, of a kind used in apparel, as furnishing fabrics or for similar purposes, } \\
\text { n.e.s }\end{array}$ \\
\hline 581010 & $\begin{array}{l}\text { Embroidery on a textile fabric ground without visible ground, in the piece, in } \\
\text { strips or in motifs }\end{array}$ \\
\hline 581091 & $\begin{array}{l}\text { Embroidery of cotton on a textile fabric ground, in the piece, in strips or in motifs } \\
\text { (excl. embroidery without visible ground) }\end{array}$ \\
\hline 581092 & $\begin{array}{l}\text { Embroidery of man-made fibres on a textile fabric base, in the piece, in strips or in } \\
\text { motifs (excl. embroidery without visible ground) }\end{array}$ \\
\hline 581099 & $\begin{array}{l}\text { Embroidery of materials other than cotton or man-made fibres, on a textile fabric } \\
\text { base, in the piece, in strips or in motifs (excl. embroidery without visible } \\
\text { ground) }\end{array}$ \\
\hline 581100 & $\begin{array}{l}\text { Quilted textile products in the piece, composed of one or more layers of textile } \\
\text { materials assembled with padding by stitching or otherwise (excl. embroidery of } \\
\text { heading } 5810 \text { and quilted fabrics for bedding and furnishings) }\end{array}$ \\
\hline 600240 & $\begin{array}{l}\text { Knitted or crocheted fabrics, of a width of }<=30 \mathrm{~cm} \text {, containing }>=5 \% \text { by } \\
\text { weight elastomeric yarn (excl. containing rubber thread, pile fabrics, incl. "long } \\
\text { pile", looped pile fabrics, labels, badges and similar articles, and knitted or } \\
\text { crocheted fabri... }\end{array}$ \\
\hline 600290 & $\begin{array}{l}\text { Knitted or crocheted fabrics, of a width of }<=30 \mathrm{~cm} \text {, containing }>=5 \% \text { by } \\
\text { weight elastomeric yarn and rubber thread or rubber thread only (excl. pile } \\
\text { fabrics, incl. "long pile", looped pile fabrics, labels, badges and similar articles, } \\
\text { and knitted or c... }\end{array}$ \\
\hline 600310 & $\begin{array}{l}\text { Knitted or crocheted fabrics of wool or fine animal hair, of a width of }<=30 \mathrm{~cm} \\
\text { (excl. those containing by weight }>=5 \% \text { of elastomeric yarn or rubber thread, } \\
\text { and pile fabrics, incl. "long pile", looped pile fabrics, labels, badges and similar } \\
\text { article... }\end{array}$ \\
\hline
\end{tabular}


Table 14 (continued)

Code Label

600320

600330

600340

600390

600410

600490

630240

630411

630491

630800

CERO03

CER015

370610

370690

CER016

852410

852432

852439

852451
Knitted or crocheted fabrics of cotton, of a width of $<=30 \mathrm{~cm}$ (excl. those containing by weight $>=5 \%$ of elastomeric yarn or rubber thread, and pile fabrics, incl. "long pile", looped pile fabrics, labels, badges and similar articles, and knitted or ...

Knitted or crocheted fabrics of synthetic fibres, of a width of $<=30 \mathrm{~cm}$ (excl. those containing by weight $>=5 \%$ of elastomeric yarn or rubber thread, and pile fabrics, incl. "long pile", looped pile fabrics, labels, badges and similar articles, and $\mathrm{k} . .$.

Knitted or crocheted fabrics of artificial fibres, of a width of $<=30 \mathrm{~cm}$ (excl. those containing by weight $>=5 \%$ of elastomeric yarn or rubber thread, and pile fabrics, incl. "long pile", looped pile fabrics, labels, badges and similar articles, and ....

Knitted or crocheted fabrics of a width of $<=30 \mathrm{~cm}$ (excl. of cotton, artificial fibres, wool or fine animal hair, those containing by weight $>=5 \%$ of elastomeric yarn or rubber thread, and pile fabrics, incl. "long pile", looped pile fabrics, labels,...

Knitted or crocheted fabrics, of a width of $>30 \mathrm{~cm}$, containing $>=5 \%$ by weight elastomeric yarn (excl. containing rubber thread, pile fabrics, incl. "long pile", looped pile fabrics, labels, badges and similar articles, and knitted or crocheted fabric...

Knitted or crocheted fabrics, of a width of $>30 \mathrm{~cm}$, containing $>=5 \%$ by weight elastomeric yarn and rubber thread or rubber thread only (excl. pile fabrics, incl. "long pile", looped pile fabrics, labels, badges and similar articles, and knitted or cr...

Bed-linen of man-made fibres (excl. printed, knitted or crocheted)

Table linen, knitted or crocheted

Knitted or crocheted bedspreads (excl. bed-linen, quilts and eiderdowns)

Articles for interior furnishing, knitted or crocheted (excl. blankets and travelling rugs, bed-linen, table linen, toilet linen, kitchen linen, curtains, incl. drapes, interior blinds, curtain or bed valances, bedspreads, lampshades and articles of he...

Sets consisting of woven fabric and yarn, whether or not with accessories, for making up into rugs, tapestries, embroidered table cloths or serviettes, or similar textile articles, put up in packings for retail sale (excl. sets for making up into artic...

\section{Audio Visuals}

Film

Cinematographic film, exposed and developed, whether or not incorporating sound track or consisting only of sound track, width $>=35 \mathrm{~mm}$

Cinematographic film, exposed and developed, whether or not incorporating sound track or consisting only of sound track, width $<35 \mathrm{~mm}$

CD, DVD, Tapes

Gramophone records

Discs, recorded, for laser reading systems, for reproducing sound only

Discs, recorded, for laser reading systems, for reproducing sound and image or image only

Magnetic tapes for reproducing sound or image, recorded, of a width $<=4 \mathrm{~mm}$ 
Table 14 (continued)

\begin{tabular}{ll}
\hline Code & Label \\
\hline 852452 & $\begin{array}{l}\text { Magnetic tapes for reproducing sound or image, recorded, of a width }>4 \mathrm{~mm} \\
\text { but }<=6,5 \mathrm{~mm}\end{array}$ \\
852453 & Magnetic tapes for reproducing sound or image, recorded, of a width $>6,5 \mathrm{~mm}$ \\
CER004 & Design \\
CER017 & Architecture \\
490600 & $\begin{array}{l}\text { Plans and drawings for architectural, engineering, industrial, commercial, topo- } \\
\text { graphical or similar purposes, being originals drawn by hand; hand-written } \\
\text { texts; photographic reproductions on sensitised paper and carbon copies of the } \\
\text { foregoing }\end{array}$
\end{tabular}

CERO18

420211

611720

611780

611790

621410

\section{Fashion}

Trunks, suit-cases, vanity-cases, executive-cases, brief-cases, school satchels and similar containers, with outer surface of leather, composition leather or patent leather

Trunks, suit-cases, vanity-cases, executive-cases, brief-cases, school satchels and similar containers, with outer surface of plastics or textile materials

Handbags, whether or not with shoulder straps, incl. those without handles, with outer surface of leather, composition leather or patent leather

Handbags, whether or not with shoulder straps, incl. those without handles, with outer surface of plastic sheeting or textile materials

Wallets, purses, key-pouches, cigarette-cases, tobacco-pouches and similar articles carried in the pocket or handbag, with outer surface of leather, composition leather or patent leather

Wallets, purses, key-pouches, cigarette-cases, tobacco-pouches and similar articles carried in the pocket or handbag, with outer surface of plastic sheeting or textile materials

Travelling-bags, insulated food or beverage bags, toilet bags, rucksacks, shoppingbags, map-cases, tool bags, sports bags, jewellery boxes, cutlery cases, binocular cases, camera cases, musical instrument cases, gun cases, holsters and similar contain...

Articles of apparel, of leather or composition leather (excl. clothing accessories, footware and headgear and parts thereof, and goods of chapter 95, e.g. shin guards, fencing masks)

Gloves, mittens and mitts, of leather or composition leather (excl. special sports gloves)

Belts and bandoliers, of leather or composition leather

Clothing accessories of leather or composition leather (excl. gloves, mittens and mitts, belts, bandoliers, footware and headgear and parts thereof, and goods of chapter 95 [e.g. shin guards, fencing masks])

Articles of apparel and clothing accessories of furskin (excl. gloves made of leather and furskin, footware and headgear and parts thereof)

Shawls, scarves, mufflers, mantillas, veils and the like, knitted or crocheted

Ties, bow ties and cravats, knitted or crocheted

Made up clothing accessories, knitted or crocheted, n.e.s. (excl. shawls, scarves, mufflers, mantillas, veils and the like, ties, bow ties and cravats)

Parts of garments or clothing accessories, knitted or crocheted, n.e.s

Shawls, scarves, mufflers, mantillas, veils and similar articles of silk or silk waste (excl. knitted or crocheted) 
Table 14 (continued)

\begin{tabular}{ll}
\hline Code & Label \\
\hline 621420 & $\begin{array}{l}\text { Shawls, scarves, mufflers, mantillas, veils and similar articles of wool or fine } \\
\text { animal hair (excl. knitted or crocheted) }\end{array}$ \\
621430 & $\begin{array}{l}\text { Shawls, scarves, mufflers, mantillas, veils and similar articles of synthetic fibres } \\
\text { (excl. knitted or crocheted) }\end{array}$ \\
621440 & $\begin{array}{l}\text { Shawls, scarves, mufflers, mantillas, veils and similar articles of artificial fibres } \\
\text { (excl. knitted or crocheted) }\end{array}$ \\
621490 & $\begin{array}{l}\text { Shawls, scarves, mufflers, mantillas, veils and similar articles of textile materials } \\
\text { (excl. of silk, silk waste, wool, fine animal hair or man-made fibres, knitted or } \\
\text { crocheted) }\end{array}$
\end{tabular}

Ties, bow ties and cravats of silk or silk waste (excl. knitted or crocheted)

Ties, bow ties and cravats of man-made fibres (excl. knitted or crocheted)

621590

Ties, bow ties and cravats of textile materials (excl. of silk, silk waste or manmade fibres, knitted or crocheted)

Made up clothing accessories, of all types of textile materials, n.e.s. (excl. knitted or crocheted)

Parts of garments or clothing accessories, of all types of textile materials, n.e.s. (excl. knitted or crocheted)

Felt hats and other felt headgear, made from the hat bodies, hoods or plateaux of heading 6501, whether or not lined or trimmed (excl. made by assembling strips or pieces of felt, and toy and carnival headgear)

Hats and other headgear, plaited or made by assembling strips of any material, whether or not lined or trimmed (excl. headgear for animals, and toy and carnival headgear)

Hats and other headgear, knitted or crocheted, or made-up from lace, felt or other textile fabric, in the piece (but not in strips), whether or not lined or trimmed (excl. hair-nets, headgear for animals, and toy and fancy-dress headgear)

Headgear of furskin, whether or not lined or trimmed (excl. toy and carnival headgear)

Headgear, whether or not lined or trimmed, n.e.s

Sunglasses

\section{Glassware}

Glassware of glass-ceramics, of a kind used for table, kitchen, toilet, office, indoor decoration or similar purposes (excl. goods of heading 7018, cooking hobs, leaded lights and the like, lighting fittings and parts thereof, atomizers for perfume and...

Drinking glasses of lead crystal

Glassware of lead crystal, of a kind used for table or kitchen purposes (excl. articles of heading 7018, drinking glasses, glass preserving jars "sterilizing jars", vacuum flasks and other vacuum vessels)

Glassware for table or kitchen purposes of glass having a linear coefficient of expansion $<=5 \times 10-6$ per kelvin within a temperature range of $0-300{ }^{\circ} \mathrm{C}(\mathrm{excl}$. glassware of glass-ceramics or lead crystal, articles of heading 7018, drinking glasses,...

Glassware, of lead crystal, of a kind used for toilet, office, indoor decoration or similar purposes (excl. glassware of a kind used for table or kitchen purposes, glassware of glass-ceramics or lead crystal, articles of heading 7018, mirrors, leaded $1 . .$. 
Table 14 (continued)

\begin{tabular}{|c|c|}
\hline Code & Label \\
\hline 441900 & $\begin{array}{l}\text { Tableware and kitchenware, of wood (excl. interior fittings, ornaments, cooperage } \\
\text { products, tableware and kitchenware components of wood, brushes, brooms and } \\
\text { hand sieves) }\end{array}$ \\
\hline 481420 & $\begin{array}{l}\text { Wallpaper and similar wall coverings of paper, consisting of paper coated or } \\
\text { covered, on the face side, with a grained, embossed, coloured or design-printed } \\
\text { or otherwise decorated layer of plastics }\end{array}$ \\
\hline 481430 & $\begin{array}{l}\text { Wallpaper and similar wall coverings of paper, consisting of paper covered, on } \\
\text { the face side, with plaiting material, whether or not bound together in parallel } \\
\text { strands or woven }\end{array}$ \\
\hline 570310 & $\begin{array}{l}\text { Carpets and other floor coverings, of wool or fine animal hair, tufted "needle } \\
\text { punched", whether or not made-up }\end{array}$ \\
\hline 570390 & $\begin{array}{l}\text { Carpet tiles of vegetable textile materials or coarse animal hair, tufted "needle } \\
\text { punched", whether or not made-up }\end{array}$ \\
\hline 570410 & Floor tiles, of felt, not tufted or flocked, with an area of $<=0,3 \mathrm{~m}^{2}$ \\
\hline 570500 & $\begin{array}{l}\text { Carpets and other textile floor coverings, whether or not made-up (excl. knotted, } \\
\text { woven or tufted "needle punched", and of felt) }\end{array}$ \\
\hline 580410 & Tulles and other net fabrics (excl. woven, knitted or crocheted fabrics) \\
\hline 580421 & $\begin{array}{l}\text { Mechanically made lace of man-made fibres in the piece, in strips or in motifs } \\
\text { (excl. fabrics of heading 6002-6006) }\end{array}$ \\
\hline
\end{tabular}

Mechanically made lace in the piece, in strips or in motifs (excl. that of man-made fibres and fabrics of heading 6002-6006)

Textile wall coverings

691110

Tableware and kitchenware, of porcelain or china (excl. ornamental articles, pots, jars, carboys and similar receptacles for the conveyance or packing of goods, and coffee grinders and spice mills with receptacles made of ceramics and working parts of ...

Tableware, kitchenware, other household articles and toilet articles, of ceramics other than porcelain or china (excl. baths, bidets, sinks and similar sanitary fixtures, statuettes and other ornamental articles, pots, jars, carboys and similar recepta...

Ceramic articles of porcelain or china, n.e.s

Sets of spoons, forks or other articles of heading 8215 , which may also contain up to an equivalent number of knives, of base metal, containing at least one article plated with precious metal

Sets of spoons, forks or other articles of heading 8215 , incl. those with up to an equal number of knives, of base metal, containing no articles plated with precious metal

Spoons, forks, ladles, skimmers, cake-servers, fish-knives, butter-knives, sugar tongs and similar kitchen or tableware of base metal, plated with precious metal (excl. sets of articles such as lobster cutters and poultry shears)

Metal furniture (excl. for offices, seats and medical, surgical, dental or veterinary furniture)

$940340 \quad$ Wooden furniture for kitchens (excl. seats)

Furniture of cane, osier, bamboo or similar materials (excl. of metal, wood and plastics) 
Table 14 (continued)

\begin{tabular}{ll}
\hline Code & Label \\
\hline 940510 & $\begin{array}{c}\text { Chandeliers and other electric ceiling or wall lighting fittings (excl. for lighting } \\
\text { public open spaces or thoroughfares) }\end{array}$ \\
940530 & Electric lighting sets of a kind used for Christmas trees \\
CER021 & Jewellery
\end{tabular}

Articles of jewellery and parts thereof, of silver, whether or not plated or clad with other precious metal (excl. articles $>100$ years old)

Articles of jewellery and parts thereof, of precious metal other than silver, whether or not plated or clad with precious metal (excl. articles $>100$ years old)

Articles of jewellery and parts thereof, of base metal clad with precious metal (excl. articles $>100$ years old)

Articles of goldsmiths' or silversmiths' wares or parts thereof, of silver, whether or not plated or clad with other precious metal (excl. jewellery, watch-and clockmakers' wares, musical instruments, weapons, perfume atomizers and heads for these, ori...

Articles of goldsmiths' or silversmiths' wares or parts thereof, of precious metal other than silver, whether or not plated or clad with precious metal (excl. jewellery, watch- and clockmakers' wares, musical instruments, weapons, perfume atomizers and...

Articles of goldsmiths' or silversmiths' wares and parts thereof, of base metal clad with precious metal (excl. jewellery, watch-and clockmakers' wares, musical instruments, weapons, perfume atomizers and heads for these, original sculptures or statuar...

Articles of natural or cultured pearls, n.e.s

Articles of precious or semi-precious stones "natural, synthetic or reconstructed", n.e.s

Cuff-links and studs, of base metal, whether or not clad with silver, gold or platinum

Imitation jewellery, of base metal, whether or not plated with precious metal (excl. cuff-links and studs)

CERO22

Toys

950100

Wheeled toys designed to be ridden by children, e.g. tricycles, scooters, pedal cars (excl. normal bicycles with ball bearings); dolls' carriages

Dolls representing only human beings, whether or not clothed

Garments and accessories, footwear and headgear for dolls representing only human beings

Parts and accessories for dolls representing only human beings, n.e.s

Electric trains, incl. tracks, signals and other accessories therefor

Scale model assembly kits, whether or not working models (excl. electric trains, incl. tracks, signals and other accessories therefor)

Construction sets and constructional toys (excl. scale model assembly kits)

Stuffed toys representing animals or non-human creatures

Toys representing animals or non-human creatures (excl. stuffed)

Toy musical instruments and apparatus

\section{Puzzles}

Toys, put up in sets or outfits (excl. electric trains, incl. accessories, scale model assembly kits, construction sets and constructional toys, and puzzles) 
Table 14 (continued)

\begin{tabular}{|c|c|}
\hline Code & Label \\
\hline 950380 & $\begin{array}{l}\text { Toys and models, incorporating a motor (excl. electric trains, scale model assem- } \\
\text { bly kits, and toys representing animals, human or non-human creatures) }\end{array}$ \\
\hline 950390 & Toys, n.e.s \\
\hline 950420 & Billiards and accessories \\
\hline 950440 & Playing cards \\
\hline 950490 & $\begin{array}{l}\text { Tables for casino games, automatic bowling alley equipment, and other funfair, } \\
\text { table or parlour games, incl. pintables (excl. operated by coins, banknotes "paper } \\
\text { currency", discs or other similar articles, billiards, video games for use with a } \\
\text { televisi... }\end{array}$ \\
\hline CER005 & New media \\
\hline CERO23 & Recorded media \\
\hline 852460 & Cards incorporating a recorded magnetic stripe \\
\hline 852499 & $\begin{array}{l}\text { Recorded media for sound or image reproducing phenomena, incl. matrices and } \\
\text { masters for the production of records (excl. gramophone records, discs for laser } \\
\text { reading systems, magnetic tapes, cards incorporating a magnetic stripe and } \\
\text { goods of chapter } 37 \text { ) }\end{array}$ \\
\hline 854381 & $\begin{array}{l}\text { Proximity cards and tags, generally consisting of an integrated circuit with a read } \\
\text { only memory attached to a printed antenna }\end{array}$ \\
\hline CERO24 & Video games \\
\hline 950410 & Video games for use with a television receiver \\
\hline 950430 & $\begin{array}{l}\text { Games with screens, flipper and other games, operated by coins, banknotes "paper } \\
\text { currency", discs or other similar articles (excl. bowling alley equipment) }\end{array}$ \\
\hline CER006 & Performing arts \\
\hline CER025 & Musical instruments \\
\hline 830610 & Bells, gongs and the like, non-electric, of base metal (excl. musical instruments) \\
\hline 920110 & Upright pianos \\
\hline 920120 & Grand pianos \\
\hline 920190 & Harpsichords and other keyboard stringed instruments (excl. pianos) \\
\hline 920210 & Violins and other string instruments \\
\hline 920290 & $\begin{array}{l}\text { Guitars, harps and other string musical instruments (excl. with keyboard and those } \\
\text { played with a bow) }\end{array}$ \\
\hline 920510 & Brass-wind instruments \\
\hline 920590 & Wind musical instruments (excl. organs and brass-wind instruments) \\
\hline 920600 & $\begin{array}{l}\text { Percussion musical instruments, e.g. drums, xylophones, cymbals, castanets, } \\
\text { maracas }\end{array}$ \\
\hline 920710 & $\begin{array}{l}\text { Keyboard instruments, the sound of which is produced, or must be amplified, } \\
\text { electrically (excl. accordions) }\end{array}$ \\
\hline 920790 & $\begin{array}{l}\text { Accordions and musical instruments without keyboards, the sound of which is } \\
\text { produced, or must be amplified, electrically }\end{array}$ \\
\hline 920810 & Musical boxes \\
\hline 920890 & $\begin{array}{l}\text { Fairground organs, mechanical street organs, mechanical singing birds, musi- } \\
\text { cal saws and other musical instruments not falling within any other heading in } \\
\text { chapter 92; decoy calls of all kinds; whistles, call horns and other mouth-blown } \\
\text { sound signalling ... }\end{array}$ \\
\hline CERO26 & Printed music \\
\hline 490400 & Music, printed or in manuscript, whether or not bound or illustrated \\
\hline
\end{tabular}


Table 14 (continued)

\begin{tabular}{|c|c|}
\hline Code & Label \\
\hline CERO07 & Publishing \\
\hline CER027 & Books \\
\hline 490110 & $\begin{array}{l}\text { Printed books, brochures and similar printed matter, in single sheets, whether or } \\
\text { not folded (excl. periodicals and publications which are essentially devoted to } \\
\text { advertising) }\end{array}$ \\
\hline 490191 & Dictionaries and encyclopaedias, and serial instalments thereof \\
\hline 490199 & $\begin{array}{l}\text { Printed books, brochures and similar printed matter (excl. those in single sheets; } \\
\text { dictionaries, encyclopaedias, periodicals and publications which are essentially } \\
\text { devoted to advertising) }\end{array}$ \\
\hline 490300 & Children's picture, drawing or colouring books \\
\hline CERO28 & Newspaper \\
\hline 480100 & $\begin{array}{l}\text { Newsprint, in rolls of a width }>36 \mathrm{~cm} \text { or in square or rectangular sheets with one } \\
\text { side }>36 \mathrm{~cm} \text { and the other side }>15 \mathrm{~cm} \text { in the unfolded state }\end{array}$ \\
\hline 490210 & $\begin{array}{l}\text { Newspapers, journals and periodicals, whether or not illustrated or containing } \\
\text { advertising material, appearing at least four times a week }\end{array}$ \\
\hline 490290 & $\begin{array}{l}\text { Newspapers, journals and periodicals, whether or not illustrated or containing } \\
\text { advertising material (excl. those appearing at least four times a week) }\end{array}$ \\
\hline CER029 & Other printed matter \\
\hline 490510 & Globes, printed (excl. relief globes) \\
\hline 490591 & $\begin{array}{l}\text { Maps and hydrographic or similar charts of all kinds, incl. atlases and topographi- } \\
\text { cal plans, printed and in book form (excl. globes, and maps and plans, in relief) }\end{array}$ \\
\hline 490599 & $\begin{array}{l}\text { Maps and hydrographic or similar charts of all kinds, incl. atlases, wall maps and } \\
\text { topographical plans, printed (excl. those in book form, and maps, plans and } \\
\text { globes, in relief) }\end{array}$ \\
\hline 490810 & Transfers "decalcomanias", vitrifiable \\
\hline 490890 & Transfers "decalcomanias" (excl. vitrifiable) \\
\hline 490900 & $\begin{array}{l}\text { Printed or illustrated postcards; printed cards bearing personal greetings, mes- } \\
\text { sages or announcements, whether or not illustrated, with or without envelopes } \\
\text { or trimmings }\end{array}$ \\
\hline 491000 & Calendars of any kinds, printed, incl. calendars blocks \\
\hline 491110 & Trade advertising material, commercial catalogues and the like \\
\hline CER008 & Visual arts \\
\hline CER030 & Antiques \\
\hline 970400 & $\begin{array}{l}\text { Postage or revenue stamps, stamp-postmarks, first-day covers, postal stationery, } \\
\text { stamped paper and the like, used, or if unused, not of current or new issue in } \\
\text { which they have, or will have, a recognised face value }\end{array}$ \\
\hline 970500 & $\begin{array}{l}\text { Collections and collector's pieces of zoological, botanical, mineralogical, ana- } \\
\text { tomical, historical, archaeological, palaeontological, ethnographic or numis- } \\
\text { matic interest }\end{array}$ \\
\hline 970600 & Antiques of $>100$ years old \\
\hline CER031 & Paintings \\
\hline 970110 & $\begin{array}{l}\text { Paintings, e.g. oil paintings, watercolours and pastels, and drawings executed } \\
\text { entirely by hand (excl. technical drawings and the like of heading 4906, and } \\
\text { hand-painted or hand-decorated manufactured articles) }\end{array}$ \\
\hline 970190 & Collages and similar decorative plaques \\
\hline 970200 & Original engravings, prints and lithographs \\
\hline
\end{tabular}


Table 14 (continued)

\begin{tabular}{ll}
\hline Code & Label \\
\hline CER032 & $\begin{array}{l}\text { Photography } \\
\text { Photographic plates and film, exposed and developed, for offset reproduction } \\
\text { (excl. products made of paper, paperboard or textiles and ready-to-use plates) } \\
\text { Microfilm, exposed and developed (excl. microfilm for offset reproduction) }\end{array}$ \\
370520 & $\begin{array}{l}\text { Photographic plates and film, exposed and developed (excl. products made of } \\
\text { paper, paperboard or textiles, cinematographic film, film for offset reproduction } \\
\text { and microfilm) }\end{array}$ \\
$\begin{array}{l}\text { Pictures, prints and photographs, n.e.s } \\
\text { CER033 }\end{array}$ & $\begin{array}{l}\text { Sculpture } \\
\text { Statuettes and other ornamental articles, of plastics } \\
492640\end{array}$ \\
$\begin{array}{l}\text { Statuettes and other ornaments, of wood (excl. wood marquetry and inlaid wood) } \\
\text { Statuettes and other ornamental articles of porcelain or china, n.e.s }\end{array}$ \\
$\begin{array}{l}\text { Statuettes and other ornamental ceramic articles, n.e.s. (excl. of porcelain or } \\
\text { china) }\end{array}$ \\
$\begin{array}{l}\text { Statuettes and other ornaments, of base metal, plated with precious metal (excl. } \\
\text { works of art, collectors' pieces and antiques) }\end{array}$ \\
$\begin{array}{l}\text { Statuettes and other ornaments, of base metal, not plated with precious metal } \\
\text { (excl. works of art, collectors' pieces and antiques) }\end{array}$ \\
Original sculptures and statuary, in any material
\end{tabular}

UNESCO classification of core cultural goods

$970600 \begin{aligned} & \text { Antiques of an age exceeding one Antiques } \\ & \text { hundred years }\end{aligned}$

970500 Collections and collectors' pieces of Antiques A. Cultural and natural heritage zoological, botanical, mineralogical, anatomical, historical, archaeological, palaeontological, ethnographic or numismatic interest

830610 Bells, gongs and the like

Musical instruments B. Performance and celebration

920110 Upright pianos

920120 Grand pianos

920190 Harpsichords and other keyboard stringed instruments (excl. pianos)

920210 Other string musical instruments (for example violins, harps) played with a bow

920290 Guitars, harps and other string musical instruments (excl. with keyboard and those played with a bow)

920510 Brass wind instruments (for example, clarinets, trumpets bagpipes)

920590 Wind musical instruments (excl. brasswind instruments)

920600 Percussion musical instruments

Musical instruments B. Performance and celebration

Musical instruments B. Performance and celebration

Musical instruments B. Performance and celebration

Musical instruments B. Performance and celebration

Musical instruments B. Performance and celebration

Musical instruments B. Performance and celebration

Musical instruments B. Performance and celebration

Musical instruments B. Performance and celebration (for example drums, xylophones, cymbals,castanets, maracas) 
Table 14 (continued)

\begin{tabular}{|c|c|c|c|}
\hline HS07 & Description & Domain & Macro category \\
\hline 920710 & $\begin{array}{l}\text { Keyboard instruments other than } \\
\text { accordions }\end{array}$ & Musical instruments & B. Performance and celebration \\
\hline 920790 & $\begin{array}{l}\text { Accordions and musical instruments } \\
\text { without keyboards, the sound of } \\
\text { which is produced, or must be ampli- } \\
\text { fied, electrically }\end{array}$ & Musical instruments & B. Performance and celebration \\
\hline 920810 & Musical boxes & Musical instruments & B. Performance and celebration \\
\hline 920890 & $\begin{array}{l}\text { Fairground organs, mechanical street } \\
\text { organs, mechanical singing birds, } \\
\text { musical saws and other musical } \\
\text { instrument; decoy calls of all kinds; } \\
\text { whistles, call horn and other mouth } \\
\text { blown sound signalling instruments }\end{array}$ & Musical instruments & B. Performance and celebration \\
\hline 852321 & Cards incorporating a magnetic stripe & Recorded media & B. Performance and celebration \\
\hline 852329 & $\begin{array}{l}\text { Magnetic media for the recording of } \\
\text { sound or of other phenomena (excl. } \\
\text { cards incorporating a magnetic stripe } \\
\text { and goods of chapter } 37 \text { ) }\end{array}$ & Recorded media & B. Performance and celebration \\
\hline 852351 & $\begin{array}{l}\text { Solid-state non-volatile storage } \\
\text { devices }\end{array}$ & Recorded media & B. Performance and celebration \\
\hline 852359 & $\begin{array}{l}\text { Semiconductor media, unrecorded, for } \\
\text { the recording of sound or of other } \\
\text { phenomena }\end{array}$ & Recorded media & B. Performance and celebration \\
\hline 852380 & $\begin{array}{l}\text { Gramophone records and other media } \\
\text { for the recording of sound or of } \\
\text { other phenomena, whether or not } \\
\text { recorded, incl. matrices and masters } \\
\text { for the production of discs }\end{array}$ & Recorded media & B. Performance and celebration \\
\hline 490400 & $\begin{array}{l}\text { Music, printed or in manuscript, } \\
\text { whether or not bound or illustrated }\end{array}$ & Recorded media & B. Performance and celebration \\
\hline 970110 & $\begin{array}{l}\text { Paintings, drawings and pastels, } \\
\text { executed entirely by hand, other than } \\
\text { drawings of heading } 4906 \text { and other } \\
\text { than hand-painted or hand-decorated } \\
\text { manufactured articles, collages and } \\
\text { similar decorative plaques }\end{array}$ & Paintings & C. Visual arts and crafts \\
\hline 970190 & $\begin{array}{l}\text { Collages and similar decorative } \\
\text { plaques }\end{array}$ & Paintings & C. Visual arts and crafts \\
\hline 491191 & Pictures, designs and photographs & Paintings & C. Visual arts and crafts \\
\hline 970200 & $\begin{array}{l}\text { Original engravings, prints and } \\
\text { lithographs }\end{array}$ & Other visual arts & C. Visual arts and crafts \\
\hline 970300 & $\begin{array}{l}\text { Original sculptures and statuary, in } \\
\text { any material }\end{array}$ & Other visual arts & C. Visual arts and crafts \\
\hline 392640 & $\begin{array}{l}\text { Statuettes and other ornamental arti- } \\
\text { cles in plastic }\end{array}$ & Other visual arts & C. Visual arts and crafts \\
\hline 442010 & $\begin{array}{l}\text { Statuettes and other ornaments, of } \\
\text { wood }\end{array}$ & Other visual arts & C. Visual arts and crafts \\
\hline
\end{tabular}


Table 14 (continued)

\begin{tabular}{|c|c|c|c|}
\hline HS07 & Description & Domain & Macro category \\
\hline 442090 & $\begin{array}{l}\text { Wood marquetry and inlaid wood; } \\
\text { caskets and cases for jewellery } \\
\text { or cutlery, and similar articles, of } \\
\text { wood; wooden articles of furniture }\end{array}$ & Other visual arts & C. Visual arts and crafts \\
\hline 691310 & $\begin{array}{l}\text { Statuettes and other ornamental } \\
\text { ceramic articles of porcelain or } \\
\text { China }\end{array}$ & Other visual arts & C. Visual arts and crafts \\
\hline 691390 & $\begin{array}{l}\text { Statuettes and other ornamental } \\
\text { ceramic articles, n.e.s. (excl. of } \\
\text { porcelain or china) }\end{array}$ & Other visual arts & C. Visual arts and crafts \\
\hline 701890 & Glassware articles including statuettes & Other visual arts & C. Visual arts and crafts \\
\hline 830621 & $\begin{array}{l}\text { Statuettes and other ornaments, of } \\
\text { base metal plated with precious } \\
\text { metal }\end{array}$ & Other visual arts & C. Visual arts and crafts \\
\hline 830629 & $\begin{array}{l}\text { Statuettes and other ornaments, of } \\
\text { base metal, not plated with precious } \\
\text { metal (excl. works of art, collectors" } \\
\text { pieces and antiques) }\end{array}$ & Other visual arts & C. Visual arts and crafts \\
\hline 960110 & Worked ivory and ivory articles & Other visual arts & C. Visual arts and crafts \\
\hline 960190 & $\begin{array}{l}\text { Bone, tortoiseshell, horn, antlers, } \\
\text { coral, mother-of-pearl and other } \\
\text { animal carving material, and articles } \\
\text { of these materials (including articles } \\
\text { obtained by moulding) }\end{array}$ & Other visual arts & C. Visual arts and crafts \\
\hline 580500 & $\begin{array}{l}\text { Hand-woven tapestries of the type } \\
\text { Gobelins, Flanders, Aubusson, } \\
\text { Beauvais and the like and needle- } \\
\text { worked tapestries }\end{array}$ & Craft & C. Visual arts and crafts \\
\hline 580610 & $\begin{array}{l}\text { Narrow woven fabrics: woven pile fab- } \\
\text { rics (including terry towelling and } \\
\text { similar terry fabrics) and chenille } \\
\text { fabrics }\end{array}$ & Craft & C. Visual arts and crafts \\
\hline 580620 & $\begin{array}{l}\text { Narrow woven fabrics: other woven } \\
\text { fabrics, containing by weight } 5 \% \text { or } \\
\text { more of lastomeric yarn or rubber } \\
\text { thread }\end{array}$ & Craft & C. Visual arts and crafts \\
\hline 580631 & $\begin{array}{l}\text { Narrow woven fabrics: other woven } \\
\text { fabrics of cotton }\end{array}$ & Craft & C. Visual arts and crafts \\
\hline 580632 & $\begin{array}{l}\text { Narrow woven fabrics: other woven } \\
\text { fabrics of man-made fibres }\end{array}$ & Craft & C. Visual arts and crafts \\
\hline 80639 & $\begin{array}{l}\text { Narrow woven fabrics: other woven } \\
\text { fabrics of other textile materials }\end{array}$ & Craft & C. Visual arts and crafts \\
\hline 580640 & $\begin{array}{l}\text { Fabrics consisting of warp without } \\
\text { weft assembled by means of and } \\
\text { adhesive (bolducs) }\end{array}$ & Craft & C. Visual arts and crafts \\
\hline 580810 & $\begin{array}{l}\text { Braids in the piece; ornamental trim- } \\
\text { mings in the piece, without embroi- } \\
\text { dery; other than knitted or crocheted }\end{array}$ & Craft & C. Visual arts and crafts \\
\hline
\end{tabular}


Table 14 (continued)

\begin{tabular}{|c|c|c|c|}
\hline HS07 & Description & Domain & Macro category \\
\hline 580890 & $\begin{array}{l}\text { Other braids in the piece; ornamental } \\
\text { trimmings in the piece, without } \\
\text { embroidery; other than knitted or } \\
\text { crocheted }\end{array}$ & Craft & C. Visual arts and crafts \\
\hline 80900 & $\begin{array}{l}\text { Woven fabrics of metal thread and } \\
\text { woven fabrics of metallised yarn } \\
\text { of heading } 5605 \text { of a kind used in } \\
\text { apparels as furnishing fabrics or for } \\
\text { similar purposes }\end{array}$ & Craft & C. Visual arts and crafts \\
\hline 581010 & $\begin{array}{l}\text { Embroidery in the piece, in strips or in } \\
\text { motifs without visible ground }\end{array}$ & Craft & C. Visual arts and crafts \\
\hline 581091 & $\begin{array}{l}\text { Embroidery in the piece, in strips or in } \\
\text { motifs: other embroidery of cotton }\end{array}$ & Craft & C. Visual arts and crafts \\
\hline 581092 & $\begin{array}{l}\text { Embroidery in the piece, in strips or } \\
\text { in motifs: other embroidery of man- } \\
\text { made fibres }\end{array}$ & Craft & C. Visual arts and crafts \\
\hline 581099 & $\begin{array}{l}\text { Embroidery in the piece, in strips or } \\
\text { in motifs: other embroidery of other } \\
\text { textile materials }\end{array}$ & Craft & C. Visual arts and crafts \\
\hline 581100 & Quilted textile products in the piece & Craft & C. Visual arts and crafts \\
\hline 600240 & $\begin{array}{l}\text { Knitted or crocheted fabrics of a width } \\
\text { not exceeding } 30 \mathrm{~cm} \text {, containing by } \\
\text { weight } 5 \% \text { or more of lastomeric } \\
\text { yarn but not containing robber } \\
\text { thread }\end{array}$ & Craft & C. Visual arts and crafts \\
\hline 600290 & $\begin{array}{l}\text { Other knitted or crocheted fabrics } \\
\text { of a width not exceeding } 30 \mathrm{~cm} \text {, } \\
\text { containing by weight } 5 \% \text { or more of } \\
\text { lastomeric yarn or robber thread }\end{array}$ & Craft & C. Visual arts and crafts \\
\hline 600310 & $\begin{array}{l}\text { Knitted or crocheted fabrics of a width } \\
\text { not exceeding } 30 \mathrm{~cm} \text { of wool or fine } \\
\text { animal hair }\end{array}$ & Craft & C. Visual arts and crafts \\
\hline 600320 & $\begin{array}{l}\text { Knitted or crocheted fabrics of a width } \\
\text { not exceeding } 30 \mathrm{~cm} \text { of cotton }\end{array}$ & Craft & C. Visual arts and crafts \\
\hline 600330 & $\begin{array}{l}\text { Knitted or crocheted fabrics of a width } \\
\text { not exceeding } 30 \mathrm{~cm} \text { of synthetic } \\
\text { fibres }\end{array}$ & Craft & C. Visual arts and crafts \\
\hline 600340 & $\begin{array}{l}\text { Knitted or crocheted fabrics of a width } \\
\text { not exceeding } 30 \mathrm{~cm} \text { of artificial } \\
\text { fibres }\end{array}$ & Craft & C. Visual arts and crafts \\
\hline 600390 & $\begin{array}{l}\text { Other knitted or crocheted fabrics of a } \\
\text { width not exceeding } 30 \mathrm{~cm}\end{array}$ & Craft & C. Visual arts and crafts \\
\hline 600410 & $\begin{array}{l}\text { Knitted or crocheted fabrics, of a } \\
\text { width exceeding } 30 \mathrm{~cm} \text { containing } \\
\text { by weight } 5 \% \text { or more of lastomeric } \\
\text { yarn but not containing robber } \\
\text { thread }\end{array}$ & Craft & C. Visual arts and crafts \\
\hline
\end{tabular}


Table 14 (continued)

\begin{tabular}{|c|c|c|c|}
\hline HS07 & Description & Domain & Macro category \\
\hline 600490 & $\begin{array}{l}\text { Other knitted or crocheted fabrics, of } \\
\text { a width exceeding } 30 \mathrm{~cm} \text { containing } \\
\text { by weight } 5 \% \text { or more of lastomeric } \\
\text { yarn or robber thread }\end{array}$ & Craft & C. Visual arts and crafts \\
\hline 711311 & $\begin{array}{l}\text { Articles of jewellery and parts thereof } \\
\text { of silver, whether or not plated or } \\
\text { clad with other precious metal }\end{array}$ & Jewellery & C. Visual arts and crafts \\
\hline 711319 & $\begin{array}{l}\text { Articles of jewellery and parts thereof } \\
\text { of other precious metal, whether } \\
\text { or not plated or clad with precious } \\
\text { metal }\end{array}$ & Jewellery & C. Visual arts and crafts \\
\hline 711320 & $\begin{array}{l}\text { Articles of jewellery and parts thereof } \\
\text { of base metal clad with precious } \\
\text { metal }\end{array}$ & Jewellery & C. Visual arts and crafts \\
\hline 711411 & $\begin{array}{l}\text { Articles of goldsmiths' or silver- } \\
\text { smiths' wares and parts thereof of } \\
\text { silver, whether or not plated or clad } \\
\text { with other precious metal }\end{array}$ & Jewellery & C. Visual arts and crafts \\
\hline 711419 & $\begin{array}{l}\text { Articles of goldsmiths' or silver- } \\
\text { smiths' wares and parts thereof of } \\
\text { other precious metal, whether or not } \\
\text { plated or clad with precious metal }\end{array}$ & Jewellery & C. Visual arts and crafts \\
\hline 711420 & $\begin{array}{l}\text { Articles of goldsmiths' or silver- } \\
\text { smiths' wares and parts thereof of } \\
\text { base metal clad with precious metal }\end{array}$ & Jewellery & C. Visual arts and crafts \\
\hline 711610 & $\begin{array}{l}\text { Articles of natural or cultured pearls } \\
\text { Jewellery }\end{array}$ & Jewellery & C. Visual arts and crafts \\
\hline 711620 & $\begin{array}{l}\text { Articles of precious or semi-precious } \\
\text { stones (natural, synthetic or recon- } \\
\text { structed) }\end{array}$ & Jewellery & C. Visual arts and crafts \\
\hline 370510 & $\begin{array}{l}\text { Photographic plates and film, exposed } \\
\text { and developed, other than cinemato- } \\
\text { graphic film for offset reproduction }\end{array}$ & Photography & C. Visual arts and crafts \\
\hline 370590 & $\begin{array}{l}\text { Photographic plates and film, exposed } \\
\text { and developed (excl for offset } \\
\text { production) }\end{array}$ & Photography & C. Visual arts and crafts \\
\hline 490110 & $\begin{array}{l}\text { Printed reading books, brochures, } \\
\text { leaflets and similar printed matter } \\
\text { whether in single sheets whether or } \\
\text { not folded }\end{array}$ & Books & D. Books and press \\
\hline 490191 & $\begin{array}{l}\text { Dictionaries and encyclopaedias and } \\
\text { serial instalments thereof }\end{array}$ & Books & D. Books and press \\
\hline 490199 & $\begin{array}{l}\text { Printed books, brochures and similar } \\
\text { printed matter }\end{array}$ & Books & D. Books and press \\
\hline 490210 & $\begin{array}{l}\text { Newspapers, journals and periodicals, } \\
\text { whether or not illustrated or contain- } \\
\text { ing advertising material appearing at } \\
\text { least four times a week }\end{array}$ & Newspaper & D. Books and press \\
\hline 490290 & $\begin{array}{l}\text { Other newspapers, journals and } \\
\text { periodicals }\end{array}$ & Newspaper & D. Books and press \\
\hline
\end{tabular}


Table 14 (continued)

\begin{tabular}{|c|c|c|c|}
\hline HS07 & Description & Domain & Macro category \\
\hline 490300 & $\begin{array}{l}\text { Children's picture, drawing or colour- } \\
\text { ing books }\end{array}$ & Other printed matter & D. Books and press \\
\hline 490591 & $\begin{array}{l}\text { Maps and hydrographical or similar } \\
\text { charts of all kinds in book form }\end{array}$ & $\begin{array}{l}\text { Other printed } \\
\text { Matter }\end{array}$ & D. Books and press \\
\hline 490510 & $\begin{array}{l}\text { Maps and hydrographical or similar } \\
\text { charts of all kinds in globes }\end{array}$ & Other printed matter & D. Books and press \\
\hline 490599 & $\begin{array}{l}\text { Other maps and hydrographical or } \\
\text { similar charts of all kinds }\end{array}$ & Other printed matter & D. Books and press \\
\hline 490900 & $\begin{array}{l}\text { Postcards, printed or illustrated; } \\
\text { printed greeting cards }\end{array}$ & Other printed matter & D. Books and press \\
\hline 491000 & $\begin{array}{l}\text { Calendars of any kind, printed, includ- } \\
\text { ing calendar blocks }\end{array}$ & Other printed matter & D. Books and press \\
\hline 370610 & $\begin{array}{l}\text { Cinematograph film, exposed and } \\
\text { developed whether or not incorporat- } \\
\text { ing sound track or only consisting } \\
\text { of sound track of a width of } 35 \mathrm{~mm} \\
\text { or more }\end{array}$ & Film and video & $\begin{array}{l}\text { E. Audio-visual and Interactive } \\
\text { Media }\end{array}$ \\
\hline 370690 & $\begin{array}{l}\text { Cinematographic film, exposed and } \\
\text { developed, whether or not incorpo- } \\
\text { rating soundtrack or consisting only } \\
\text { of soundtrack, width }<35 \mathrm{~mm}\end{array}$ & Film and video & $\begin{array}{l}\text { E. Audio-visual and Interactive } \\
\text { Media }\end{array}$ \\
\hline 950410 & $\begin{array}{l}\text { Video games used with a television } \\
\text { receiver }\end{array}$ & Film and video & $\begin{array}{l}\text { E. Audio-visual and Interactive } \\
\text { Media }\end{array}$ \\
\hline 490600 & $\begin{array}{l}\text { Plans and drawings for architectural, } \\
\text { engineering, industrial, commercial, } \\
\text { topographical or similar purposes, } \\
\text { being originals drawn by hand; } \\
\text { hand-written texts; photographic } \\
\text { reproductions on sensitised paper } \\
\text { and carbon copies of the foregoing }\end{array}$ & $\begin{array}{l}\text { Architecture and } \\
\text { design }\end{array}$ & $\begin{array}{l}\text { F. Design and Creative Ser- } \\
\text { vices }\end{array}$ \\
\hline
\end{tabular}

In italic the groups (from CER001 to CER008) and the subgroups (from CER001 to CER033) defined by UNCTAD

of developing countries as well as time coverage. To address this issue, we check the robustness of our results by employing the "core" UNESCO classification. The product codes in both classifications are outlined in the next Table 14.

Funding Open access funding provided by Università degli Studi di Torino within the CRUI-CARE Agreement. The authors report funding from Stiftung Mercator, MEDAM project, Directorate-General for International Cooperation and Development.

Open Access This article is licensed under a Creative Commons Attribution 4.0 International License, which permits use, sharing, adaptation, distribution and reproduction in any medium or format, as long as you give appropriate credit to the original author(s) and the source, provide a link to the Creative Commons licence, and indicate if changes were made. The images or other third party material in this article are included in the article's Creative Commons licence, unless indicated otherwise in a credit line to the material. If material is not included in the article's Creative Commons licence and your intended use is not permitted by statutory regulation or exceeds the permitted use, you will need to obtain permission 
directly from the copyright holder. To view a copy of this licence, visit http://creativecommons.org/licen ses/by/4.0/.

\section{References}

Adsera, A., \& Pytlikova, M. (2015). The role of language in shaping international migration. The Economic Journal, 125(586), F49-F81

Aleksynska, M., \& Peri, G. (2014). Isolating the network effect of immigrants on trade. The World Economy, 37(3), 434-435

Baier, S. L., \& Bergstrand, H. J. (2007). Do free trade agreements actually increase members' international trade? Journal of International Economics, 71(1), 72-95

Barro, R., \& Sala-i-Martin, X. (1995). Economic growth. McGraw-Hill.

Barsbai, T., Rapoport, H., Steinmayr, A., \& Trebesch, C. (2017). The effect of labor migration on the diffusion of democracy: Evidence from a former Soviet Republic. American Economic Journal: Applied Economics, 9(3), 36-69

Bazzi, S., Fiszbein, M., \& Gebresilasse, M. (2020). Frontier culture: The roots and persistence of "rugged individualism" in the United States. Econometrica, 88(6), 2329-2368

Beine, M., Bertoli, S., Moraga, J. F-H. (2015). A practitioners' guide to gravity models of international migration. The World Economy. https://doi.org/10.1111/twec.12265

Beine, M., Docquier, F., \& Ozden, C. (2011). Diasporas. Journal of Development Economics, 95(1), 30-41

Beine, M., \& Parsons, C. (2015). Climatic factors as determinants of international migration. The Scandinavian Journal of Economics, 117(2), 723-767

Belot, M., \& Hatton, T. (2012). Skill selection and immigration in OECD countries. Scandinavian Journal of Economics, 114(4), 1105-1128

Belot, M., \& Ederveen, S. (2012). Cultural barriers in migration between OECD countries. Journal of Population Economics, 25(3), 1077-1105

Bertoli, S., \& Fernandez-Huertas Moraga, J. (2015). The size of the cliff at the border. Regional Science and Urban Economics, 51, 1-6

Bertoli, S., \& Fernandez-Huertas Moraga, J. (2013). Multilateral resistance to migration. Journal of Development Economics, 102, 79-100

Berry, J. W. (1980). Social and cultural change. Handbook of Cross-Cultural Psychology, 5, 211-279

Brewer, M. B. \& Brown, R. J. (1998). Intergroup relations. In: Gilbert, D. T., Fiske, S. T., Lindzey, G. (eds). The handbook of social psychology (Vol. 1, 2), 554-594, McGraw-Hill.

Brücker, H., Capuano, S., \& Marfouk, A. (2013). Education, gender and international migration: Insights from a panel-dataset 1980-2010. Norface Research Programme on Migration, Migration: New developments, Spring 2013. Norface Migration 31-32.

Campaniello, N. (2014). The causal effect of trade on migration: Evidence from countries of the EuroMediterranean partnership. Labour Economics, 30, 223-233

Castles, S., Ozkul, D., \& Cubas, M. (Eds.). (2015). Social transformation and migration: National and local experiences in South Korea, Turkey. Springer.

Cavalli-Sforza, L. (2001). Genes. University of California Press.

Chang, P.-L., \& Lee, H. (2018). Cultural preferences in international trade: Evidence from the globalization of Korean pop culture. Mimeo.

Disdier, A. C., Tai, S. H., Fontagné, L., \& Mayer, T. (2010). Bilateral trade of cultural goods. Review of World Economics, 145(4), 575-595

Felbermayr, G. J., \& Jung, B. (2009). The pro-trade effect of the brain drain: Sorting out confounding factors. Economics Letters, 104(2), 72-75

Felbermayr, G. J., \& Toubal, F. (2010). Cultural proximity and trade. European Economic Review, 54(2), 279-293

Fiorini, M., Giovannetti, G., Lanati, M., \& Santi, F. (2021). Asymmetric cultural proximity and greenfield FDI. The World Economy. https://doi.org/10.1111/twec.13088

Frankel, J. A., \& Romer, D. H. (1999). Does trade cause growth? American Economic Review, 89(3), 379-399

Girma, S., \& Yu, Z. (2002). The link between immigration and trade: Evidence from the United Kingdom. Review of World Economics, 138(1), 115-130 
Giuliano, P., \& Nathan, N. (2020). Understanding cultural persistence and change. The Review of Economic Studies. https://doi.org/10.1093/restud/rdaa074

Gould, D. M. (1994). Immigrant links to the home country: Empirical implications for US bilateral trade flows. The Review of Economics and Statistics, 76(2), 302-316

Guiso, L., Sapienza, P., \& Zingales, L. (2006). Does culture affect economic outcomes? Journal of Economic Perspectives, 20(2), 23-48

Guiso, L., Sapenza, P., \& Zingales, L. (2009). Cultural Biases in economic exchange. Quarterly Journal of Economics, 124(3), 1095-1131

Harris, J. H., \& Todaro, M. P. (1970). Migration, unemployment \& development: A two sector analysis. The American Economic Review, 60(1), 126-142

Hofstede, G. (2001). Culture's consequences: Comparing values, behaviors, institutions, and organizations across nations. (2nd ed.). Sage.

Head, K. \& Mayer, H. T. (2014). Gravity equations: Workhorse, toolkit, and cookbook. In: Gopinath, G., Helpman, E., Rogoff, K. S. (Eds). Handbook of international economics, Vol. 4, chapter 3, Elsevier.

Kaasa, A., Vadi, M., \& Varblane, U. (2016). A new dataset of cultural distances for European countries and regions. Research in International Business and Finance, 37, 231-241

Kennan, J., \& Walker, J. R. (2011). The effect of expected income on individual migration decisions. Econometrica, 79(1), 211-251

Larch, M., et al. (2019). Currency unions and trade: A PPML re-assessment with high-dimensional fixed effects. Oxford Bulletin of Economics and Statistics, 81(3), 487-510

Levitt, P. (1998). Social remittances: Migration driven local-level forms of cultural diffusion. International Migration Review, 32(4), 926-948

Li, C., Brodbeck, F. C., Shenkar, O., Ponzi, L. J., \& Fisch, J. H. (2017). Embracing the foreign: Cultural attractiveness and international strategy. Strategic Management Journal, 38(4), 950-971

Lind, J. T., \& Mehlum, H. (2010). With or without u? The appropriate test for a U-shaped relationship. Oxford Bulletin of Economics and Statistics, 72(1), 109-118

Mayda, A. M. (2010). International migration: A panel data analysis of the determinants of bilateral flows. Journal of Population Economics, 23(4), 1249-1274

Melitz, J., \& Toubal, F. (2014). Native language, spoken language, translation and trade. Journal of International Economics, 93(2), 351-363

Ortega, F., \& Peri, G. (2013). The role of income and immigration policies in attracting international migrants. Migration Studies, 1(1), 47-74

Rapoport, H., Sardoschau, S. \& Silve, A. (2020). Migration and cultural change (No. 8547). CESifo..

Straubhaar, J., 2002. (Re)asserting national television and national identity against the global, regional and local levels of world television. In: Chan, J.M., McIntyre, B.T. (Eds.), In search of boundaries. Communication nation-states and cultural identities. Ablex Publishing.

Shenkar, O. (2001). Cultural distance revisited: Towards a more rigorous conceptualization and measurement of cultural differences. Journal of International Business Studies, 32(3), 519-535

Santos Silva, J. M. C., \& Tenreyro, S. (2006). The log of gravity. The Review of Economics and statistics, $88(4), 641-658$

Santos Silva, J. M. C., \& Tenreyro, S. (2011). Further simulation evidence on the performance of the Poisson pseudo-maximum likelihood estimator. Economics Letters, 112(2), 220-222

Spilimbergo, A. (2009). Democracy and foreign education. American Economic Review, 99(1), 528-543

Tabellini, G. (2008). Institutions and culture. Journal of the European Economic Association, 6(2-3), 255-294

Trefler, D. (1995) The case of the missing trade and other mysteries. The American Economic Review 1029-1046.

Tung, R. L., \& Verbeke, A. (2010). Beyond Hofstede and GLOBE: Improving the quality of cross-cultural research. Journal of International Business Studies, 41(a8), 1259-1274

UNCTAD (2010) Creative economy report, available at http://unctad.org/en/Docs/ditctab20103_en.pdf

UNESCO (2009) Pessoa, J., Deloumeaux, L., Simon Ellis S. (2009). The 2009 Unesco framework for cultural statistics (FCS). Unesco Institute for Statistics.

Vertovec, S. (2011). The cultural politics of nation and migration. Annual Review of Anthropology, 40, $241-256$

Publisher's Note Springer Nature remains neutral with regard to jurisdictional claims in published maps and institutional affiliations. 